\title{
Measurements of intermediate-frequency electric and magnetic fields in households
}

Authors: Sam Aerts ${ }^{\mathrm{a}, *}$, Carolina Calderon ${ }^{\mathrm{b}}$, Blaž Valič ${ }^{\mathrm{c}}$, Myron Maslanyj ${ }^{\mathrm{b}}$, Darren Addison ${ }^{\mathrm{b}}$, Terry Mee ${ }^{b}$, Cristian Goiceanu ${ }^{b}$, Leen Verloock ${ }^{a}$, Matthias Van den Bossche ${ }^{a}$, Peter Gajšek ${ }^{c}$, Roel Vermeulen ${ }^{\mathrm{d}}$, Martin Röösli e,f, Elisabeth Cardis ${ }^{\mathrm{g}}$, Luc Martens ${ }^{\mathrm{a}}$, and Wout Joseph ${ }^{\mathrm{a}}$

${ }^{a}$ Department of Information Technology, Ghent University / iMinds, iGent - Technologiepark-Zwijnaarde 15, B-9052 Ghent, Belgium

b Centre for Radiation, Chemical and Environmental Hazards, Public Health England, Chilton, Didcot, Oxon OX11 0RQ, United Kingdom

${ }^{\mathrm{c}}$ Institute of Non-Ionizing Radiation (INIS), Pohorskega bataljona 215, Ljubljana, 1000, Slovenia

${ }^{\mathrm{d}}$ Institute for Risk Assessment Sciences, Department of Environmental Epidemiology, Utrecht University, Yalelaan 2, 3508 Utrecht, The Netherlands

e Swiss Tropical and Public Health Institute (Swiss TPH), Socinstrasse 57, P.O. Box, 4002 Basel, Switzerland

${ }^{\mathrm{f}}$ University of Basel, Petersplatz 1, 4003 Basel, Switzerland

g Barcelona Institute for Global Health (ISGlobal), and Municipal Institute of Medical Research (IMIM-Hospital del Mar), Doctor Aiguader, 88, 08003 Barcelona, Spain

* Corresponding author: sam.aerts@intec.ugent.be 


\begin{abstract}
Historically, assessment of human exposure to electric and magnetic fields has focused on the extremely-low-frequency (ELF) and radiofrequency (RF) ranges. However, research on the typically emitted fields in the intermediate-frequency (IF) range $(300 \mathrm{~Hz}$ to $1 \mathrm{MHz})$ as well as potential effects of IF fields on the human body remains limited, although the range of household appliances with electrical components working in the IF range has grown significantly (e.g., induction cookers and compact fluorescent lighting). In this study, an extensive measurement survey was performed on the levels of electric and magnetic fields in the IF range typically present in residences as well as emitted by a wide range of household appliances under real-life circumstances. Using spot measurements, residential IF field levels were found to be generally low, while the use of certain appliances at close distance $(20 \mathrm{~cm})$ may result in a relatively high exposure. Overall, appliance emissions contained either harmonic signals, with fundamental frequencies between $6 \mathrm{kHz}$ and $300 \mathrm{kHz}$, which were sometimes accompanied by regions in the IF spectrum of rather noisy, elevated field strengths, or much more capricious spectra, dominated by $50 \mathrm{~Hz}$ harmonics emanating far in the IF domain. The maximum peak field strengths recorded at $20 \mathrm{~cm}$ were $41.5 \mathrm{~V} / \mathrm{m}$ and $2.7 \mathrm{~A} / \mathrm{m}$, both from induction cookers. Finally, none of the appliance emissions in the IF range exceeded the exposure summation rules recommended by the International Commission on Non-Ionizing Radiation Protection guidelines and the International Electrotechnical Commission (IEC 62233) standard at $20 \mathrm{~cm}$ and beyond (maximum exposure quotients $\mathrm{EQ}_{\mathrm{E}} 1.0$ and $\left.\mathrm{EQ}_{\mathrm{H}} 0.13\right)$.
\end{abstract}

Keywords: Electric and magnetic fields; human exposure; intermediate frequencies; household appliances; epidemiology 
Funding: The research leading to these results has received funding from the European Community's Seventh Framework Programme (FP7/2007-2013) under grant agreement no 603794 - the GERONIMO project. 


\section{Introduction}

Electric appliances have become almost indispensable in our households. Connection to a power supply and use of electricity, however, leads to the emission of electric (EF) and magnetic fields (MF). To safeguard the general public from possible adverse health effects (such as electrostimulation) caused by $\mathrm{EF}$ and $\mathrm{MF}$ at frequencies typical for household appliances (i.e., lower than $1 \mathrm{MHz}$ ), their fields are subject to limits based on recommendations by international bodies such as the International Commission on Non-Ionizing Radiation Protection (ICNIRP, 2010) and the Institute of Electrical and Electronics Engineers (IEEE) International Committee on Electromagnetic Safety (ICES) (IEEE, 2006). Technical standardisation bodies such as the International Electrotechnical Commission (IEC) and the European Committee for Electrotechnical Standardization (CENELEC) use these guidelines as the basis for specific emission standards which enable manufacturers to demonstrate that their products are safe.

Historically, measurements of electromagnetic exposure from household appliances (e.g., Addari, 1994; Ainsbury et al., 2005; EPA, 1992; Karipidis and Martin, 2005; Leitgeb et al., 2008a; 2008b) and in residential environments (e.g., Addari, 1994; Preece et al., 1997; UKCCS, 2000; Tomitsch and Dechant, 2015) have focused on the extremely-low-frequency (ELF) range, between $1 \mathrm{~Hz}$ and $300 \mathrm{~Hz}$, as the mains frequency (i.e., $50 \mathrm{~Hz}$ or $60 \mathrm{~Hz}$ ) posed the dominant contribution. However, while the range of household appliances with electrical components working in the intermediate-frequency (IF) range $(300 \mathrm{~Hz}$ to $1 \mathrm{MHz}$ ) has grown significantly in recent years (e.g., induction cookers and compact fluorescent lighting), there is still only limited information available on either the typical strength of the IF fields emitted by household appliances and on the typical human exposure to IF fields at home (Gajšek et al., 2016; Litvak et al., 2002; WHO, 2005).

Previous research on IF field emitting sources has tended to focus either on occupational sources (Aerts et al., 2014; Floderus et al., 2002; Joseph et al., 2012a; 2012b; Liljestrand, 2003; Nelson and Ji, 1999; Van den Bossche et al., 2015; VMBG, 2003; Wilén, 2010) or on non-residential appliances such as electronic article surveillance (EAS) systems (Harris et al., 2000; Joseph et al., 2012c; Kang and Gandhi, 2003; Martínez-Búrdalo et al., 2010; Roivainen et al., 2014; Trulsson et al., 2007), smartboards, and touch screens (Van den Bossche et al., 2015). Research on residential IF sources, on the other hand, is limited. There has been some research on induction cookers (Christ et al., 2012; Kos et al., 2011; Mantiply, 1997; Stuchley and Lecuyer, 1987), energy saving lamps (Bakos et al., 2010; Nadakuduti et al., 2012; Van den Bossche et al., 2015), portable hearing units (Van den Bossche et al., 2015), plasma balls (Alanko et al., 2011), and magnetic-field measurements were performed in a brief survey (Kurokawa et al., 2004). However, no surveys have yet been performed that address specifically typical IF field levels in the home.

In this paper, the results of a residential IF field emission survey spanning 42 residences in three European countries (Belgium, Slovenia, and the United Kingdom (UK)) are presented. Typical field 
levels in the properties were assessed by measurements in the middle of the most-frequented rooms (living room, kitchen, and bedroom), as reported by residents. The IF fields emitted from a wide range of household appliances were also investigated through measurements as a function of distance performed on 279 appliances, operating under real-life circumstances. This study, which focuses on exposure characterization in everyday circumstances for epidemiological purposes, substantially extends current knowledge of typical IF fields in people's homes.

\section{Materials and methods}

\subsection{Measurement equipment}

To characterize the IF field levels in residences from household appliances, three measuring devices were used: a compact handheld meter (NFA-1000, Gigahertz Solutions, Langenzenn, Germany) and two computer-operated narrowband probes (EHP-50 and EHP-200, Narda Safety Test Solutions, Milan, Italy).

The NFA-1000 is able to (separately) measure the environmental magnetic- $(H$, in A/m) and the electricfield strength $(E$, in $\mathrm{V} / \mathrm{m})$ in the frequency range between $5 \mathrm{~Hz}$ and $1 \mathrm{MHz}$, with dynamic measurement ranges of $0.8 \mathrm{~mA} / \mathrm{m}$ to $1.6 \mathrm{~A} / \mathrm{m}$ and $0.1 \mathrm{~V} / \mathrm{m}$ to $2 \mathrm{kV} / \mathrm{m}$, respectively. Measurements can be performed wideband (i.e., over the whole frequency range) as well as narrowband (i.e., in separate frequency bands: $16.7 \mathrm{~Hz}, 50 \mathrm{~Hz}$, even harmonics up to $250 \mathrm{~Hz}$, uneven harmonics up to $250 \mathrm{~Hz}$, the remainder of frequencies below $2 \mathrm{kHz}$, and the frequency range between $2 \mathrm{kHz}$ and $1 \mathrm{MHz}$ ).

The EHP-50 (with dynamic measurement ranges of $0.005 \mathrm{~V} / \mathrm{m}-100 \mathrm{kV} / \mathrm{m}$ (E) and $0.24 \mathrm{~mA} / \mathrm{m}-8 \mathrm{kA} / \mathrm{m}(H))$ and EHP-200 $(0.02 \mathrm{~V} / \mathrm{m}-1000 \mathrm{~V} / \mathrm{m}(E)$ and $0.6 \mathrm{~mA} / \mathrm{m}-300 \mathrm{~A} / \mathrm{m}(H))$ probes were used to acquire $\mathrm{EF}$ and $\mathrm{MF}$ spectral information in their respective frequency ranges of $5 \mathrm{~Hz}-100 \mathrm{kHz}$ and $9 \mathrm{kHz}-30 \mathrm{MHz}$. When taking into account linearity, isotropy and frequency response, the expanded uncertainty $(\mathrm{k}=2)$ for the EHP probes was $8 \%$ and $15 \%$, respectively. Assuming a conservative uncertainty of $10{ }^{\circ} \mathrm{C}$ in temperature and $10 \%$ in humidity, the expanded uncertainty respectively becomes $10 \%$ and $16 \%$. Furthermore, to mitigate the uncertainty due to the spatial displacement of the X-, Y-, and Z-sensors in the EHP probes (which can amount to 28\% according to Nadakuduti et al. (2012)), the top of the probe was always directed towards the appliance under assessment (Christ et al., 2012).

The EHP probes have been designed to have no or minimum perturbation of the fields that are being measured, and the tripod used to hold the probes was made of low permittivity materials. Also, the EHP probes were connected to a laptop via an optical cable, allowing measurements to be made several metres away. Thus, perturbation of the electric field was kept to a minimum. 
To obtain a complete sweep of the frequency range relevant to the study, measurements were performed using the $2 \mathrm{kHz}$ and $100 \mathrm{kHz}$ measurement bands of the EHP-50 (i.e., $5 \mathrm{~Hz}$ to $2 \mathrm{kHz}$ and $1 \mathrm{kHz}$ to $100 \mathrm{kHz}$ ranges, respectively) and also in the frequency range $9 \mathrm{kHz}$ to $400 \mathrm{kHz}$ (further called $400 \mathrm{kHz}$ band) with the EHP-200, at a resolution bandwidth of $3 \mathrm{kHz}$. For each measurement, the maximum-hold setting was used, i.e., the maximum values were retained during a time interval until the reading stabilized (roughly 30 seconds). The $2 \mathrm{kHz}$ band was necessary to capture the $300 \mathrm{~Hz}$ to $1 \mathrm{kHz}$ range, but the results were mainly used for illustration.

\subsection{Measurement procedure}

\subsubsection{Selection of residences}

In total, 42 residences were investigated; 11 in Belgium, 16 in Slovenia, and 15 in the UK. This resulted in the measurement of the level and composition of environmental IF fields in 121 rooms and of 279 household appliances. The residences were from a convenience sample, and included detached, semidetached and attached houses as well as apartments. The residents were interviewed to obtain information related to the time spent in different rooms and the use of electrical appliances found in the residence.

\subsubsection{Spectral survey of the residence}

To obtain a general idea of the strength of environmental IF fields in the property, two spot measurements were performed in a number of rooms - usually three, and ideally the ones in which the residents reported spending most of their time - one when the room was in 'hibernation mode' (i.e., the normal state of the room when no one is at home) and one during 'maximum living mode' (i.e., all EMF sources - lights, displays, kitchen appliances, etc. - normally in the room switched on, as far as this was feasible). During both usage modes, the ELF and IF fields in the room were characterised using the EHP probes, secured to a tripod positioned in the middle of the room, at $1.5 \mathrm{~m}$ above the floor.

\subsubsection{Characterisation of IF emitting appliances}

By measuring $E$ and $H$ in the $2 \mathrm{kHz}$ to $1 \mathrm{MHz}$ band solely, the NFA-1000 meter enabled the quick identification of IF field emitting household appliances. When an appliance was identified as an IF source, the emitted IF fields were subsequently characterized with the EHP probes while the appliance was operated at settings typical for the residents. The probe was positioned in front of the face of the appliance closest to the user, or, for appliances with no preferential orientation, in front of the face where the highest exposure was detected. All measurements were taken at mid-height of the appliance, except for lighting sources, for which the measurements were performed in the direction of use (i.e., down when the lighting source was hanging from the ceiling and sideways when standing). 
In the following, the measuring distance was defined as 'the distance between the surface of the appliance and the closest point of the sensor surface' (International Electrotechnical Commission (IEC), 2005). Although some previous studies opted to focus on the exposure close to the source $(15 \mathrm{~cm}$ and closer) (Bakos et al., 2010; Christ et al., 2012; Ishihara et al., 2015; Kos et al., 2011; Nadakuduti et al., 2012; Van den Bossche et al., 2015) or on compliance measurements at $30 \mathrm{~cm}$ (IEC, 2005), in this study, measurements were executed at 20 and $50 \mathrm{~cm}$ to assess the exposure as a function of distance in a larger region of space.

\subsection{Exposure assessment}

Exposure assessment of an EF and/or MF emitting source is typically done by comparing the levels of the emitted fields to reference levels $F_{R}(f)$ (with $F=E$ or $H$, and $f$ the frequency of the field) recommended by ICNIRP (2010). Reference levels for IF fields are conservatively derived for more practical hazard assessment from basic restrictions issued in terms of the internal EF. While compliance with the reference levels ensures compliance with the basic restrictions, exceeding them does not necessarily mean non-compliance, and more detailed assessment is needed (e.g., Sunohara et al., 2015).

Furthermore, to assess the total exposure of an IF source, the contributions of the different spectral components of the emitted fields (the results at $f$ between $300 \mathrm{~Hz}$ and $2 \mathrm{kHz}$ were taken from the $2 \mathrm{kHz}$ measurement, between $2 \mathrm{kHz}$ and $9 \mathrm{kHz}$ from the $100 \mathrm{kHz}$ measurement, and between $9 \mathrm{kHz}$ and $400 \mathrm{kHz}$ from the $400 \mathrm{kHz}$ measurement) have to be added. To do this, the Exposure Quotient (EQ) was calculated following two methods: ICNIRP (2010), where the EQ is given by the sum of the weighted components (Equation (1) in Table 1) and IEC 62233:2005 (IEC, 2005), where the EQ is given by the root-sum-square (RSS) of the weighted spectral components (Equation (2) in Table 1). Only the peak field strengths $F_{\text {peak }, i}$ (measured at frequency $f_{i}$ ) which are higher than $5 \%$ of the corresponding reference level $F_{R, i}$ (e.g., for $f_{i}$ between $3 \mathrm{kHz}$ and $150 \mathrm{kHz}, E_{R, i}$ is $83 \mathrm{~V} / \mathrm{m}$ and $H_{R, i}$ is $21 \mathrm{~A} / \mathrm{m}$ ) (ICNIRP, 2010) were considered in the EQ calculation (IEC, 2005), though this threshold was not defined in the ICNIRP guidelines. 
Table 1: IEC (2005) and ICNIRP (2010) guidelines on comparing electric- (EF) and magnetic-field (MF) measurements at different frequencies lower than $10 \mathrm{MHz}$ with the reference levels. $F_{p e a k, i}$ is a spectral peak in the EF $(F=E)$ or MF $(F=H)$ at frequency $f_{i}$, for which $F_{R, i}$ is the corresponding reference level.

\begin{tabular}{|c|c|c|c|}
\hline Guidelines & Formula & Explanation & Equation $n^{\circ}$ \\
\hline ICNIRP (2010) & $E Q_{F, I C N}=\sum_{i=1}^{N} \frac{F_{\text {peak }, i}}{F_{R, i}}$ & $\begin{array}{l}\text { Frequency-weighted sum } \\
\text { restricted to } N \text { peaks } \\
\left(F_{\text {peak }, i} \text { not defined }\right)\end{array}$ & (1) \\
\hline IEC 62233:2005 & $E Q_{F, I E C}=\sqrt{\sum_{i=1}^{N}\left(\frac{F_{\text {peak }, i}}{F_{R, i}}\right)^{2}}$ & $\begin{array}{c}\text { Square root of quadratic } \\
\text { sum restricted to } N \\
\text { spectral peaks, with } \\
F_{\text {peak }, i}>0.05 \times F_{R, i}\end{array}$ & (2) \\
\hline
\end{tabular}

\section{Results and Discussion}

In this Section, first, the room measurements are discussed, then the IF characterisation of the household appliances, and finally a number of exposure-relevant appliances are considered in more detail.

\subsection{Spectral survey of residences}

A total of 121 rooms were surveyed (Table 2), with the three most common types (i.e., most visited by residents) bedrooms, kitchens, and living rooms. The wideband measurement results ( $E_{\text {wide }}$ and $H_{\text {wide }}$ ) were pooled per assessed frequency band and room usage mode (Figure 1), and for the $100 \mathrm{kHz}$ band are also discussed per most-common room type (Figure 2).

Table 2: Number of samples $\left(\mathbf{n}_{\mathbf{r}}\right)$ of each room type.

\begin{tabular}{cc}
\hline Room type & $\mathbf{n}_{\mathbf{r}}$ \\
\hline Bedroom & 40 \\
Kitchen & 35 \\
Living room & 35 \\
Corridor & 3 \\
Study & 4 \\
Utility room & 2 \\
Dining room & 2 \\
Total & 121 \\
\hline
\end{tabular}

Considering the absence of IF fields in hibernation mode, the probes' noise contributions in the $100 \mathrm{kHz}$ band (EHP-50) and $400 \mathrm{kHz}$ band (EHP-200) were at most $0.7 \mathrm{~V} / \mathrm{m}(100 \mathrm{kHz}$ : geometric mean (GM) 0.4 V/m; 400 kHz: GM 0.6 V/m) (Figure 1a) and 0.10 A/m (100 kHz: GM 0.05 A/m; 400 kHz: GM $0.09 \mathrm{~A} / \mathrm{m}$ ) (Figure $1 \mathrm{~b}$ ), respectively. With the rooms in maximum-living mode, the total electric-field 
strength in the $100 \mathrm{kHz}$ band (which comprises most fundamental frequencies $\left(f_{f}\right)$ of IF-field emissions) was on average (GM, considering all rooms) $1.2 \mathrm{~V} / \mathrm{m}$ (geometric standard deviation (GSD): 2.6), an increase of $170 \%$ over the average noise floor (Figure 1a), and maximum $9.5 \mathrm{~V} / \mathrm{m}$. However, in neither usage mode were any IF-MF emissions detected. The ELF emissions (as measured in the $2 \mathrm{kHz}$ band), on the other hand, increased on average by $65 \%\left(E_{\text {wide }}\right)$ and $40 \%\left(H_{\text {wide }}\right)$ in the maximum-living mode as opposed to hibernation mode (Figure 1b).

The same trend is observed per (most-common) room type (Figure 2). Moreover, a higher spread in $E$ wide was measured in kitchens (GSD: 3.1) and living rooms (GSD: 2.6) compared to bedrooms (GSD: 1.9) when in maximum-living mode (Figure 2a), reflecting the fact that there is a larger variety of electric appliances used in the former two. No substantial difference was observed in $H$ across the rooms (Figure 2b).

It should finally be noted that all measured values-remember that the measurements were performed at a distance of $1 \mathrm{~m}$ or more from any appliance-were very low compared to IF exposure guideline reference levels.

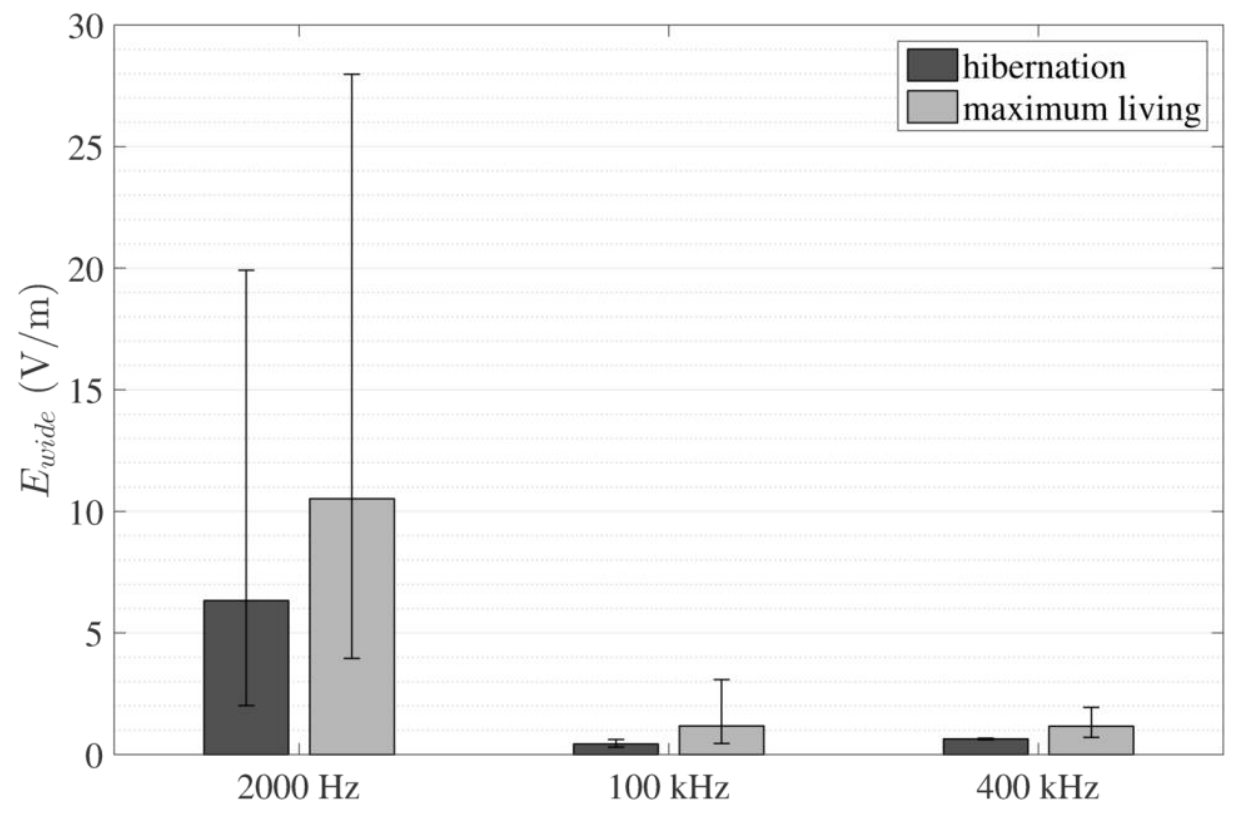

(a) 


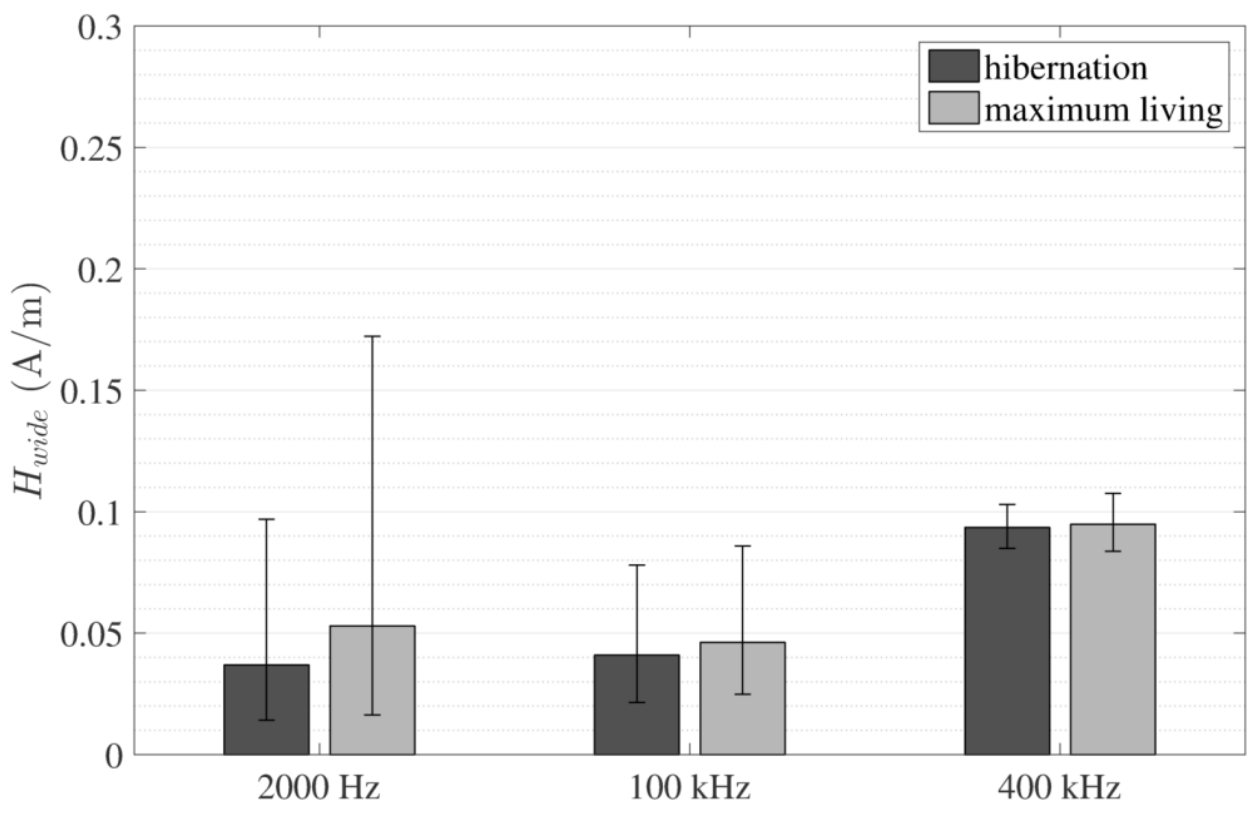

(b)

Figure 1: Geometric means (and geometric standard deviations) per frequency band (EHP-50: $2 \mathrm{kHz}$ and $100 \mathrm{kHz}$ bands; EHP-200: $400 \mathrm{kHz}$ band) and per room usage mode (hibernation/maximum living) of the (a) wideband electricfield strength measurements $\left(\boldsymbol{E}_{\text {wide }}, \mathrm{V} / \mathrm{m}\right)$ and $(\mathrm{b})$ wideband magnetic-field strength measurements $\left(H_{\text {wide }}, \mathrm{A} / \mathrm{m}\right)$, collected over all rooms (Table 2).

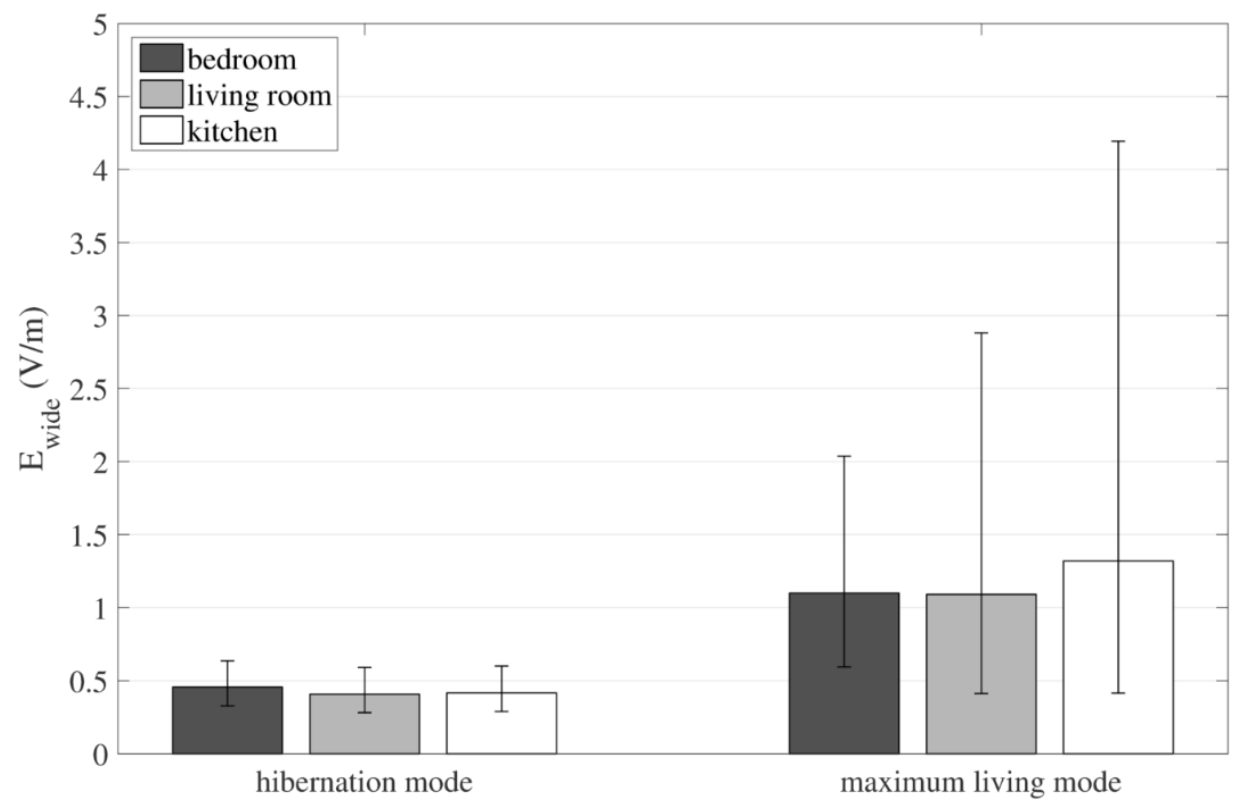

(a) 


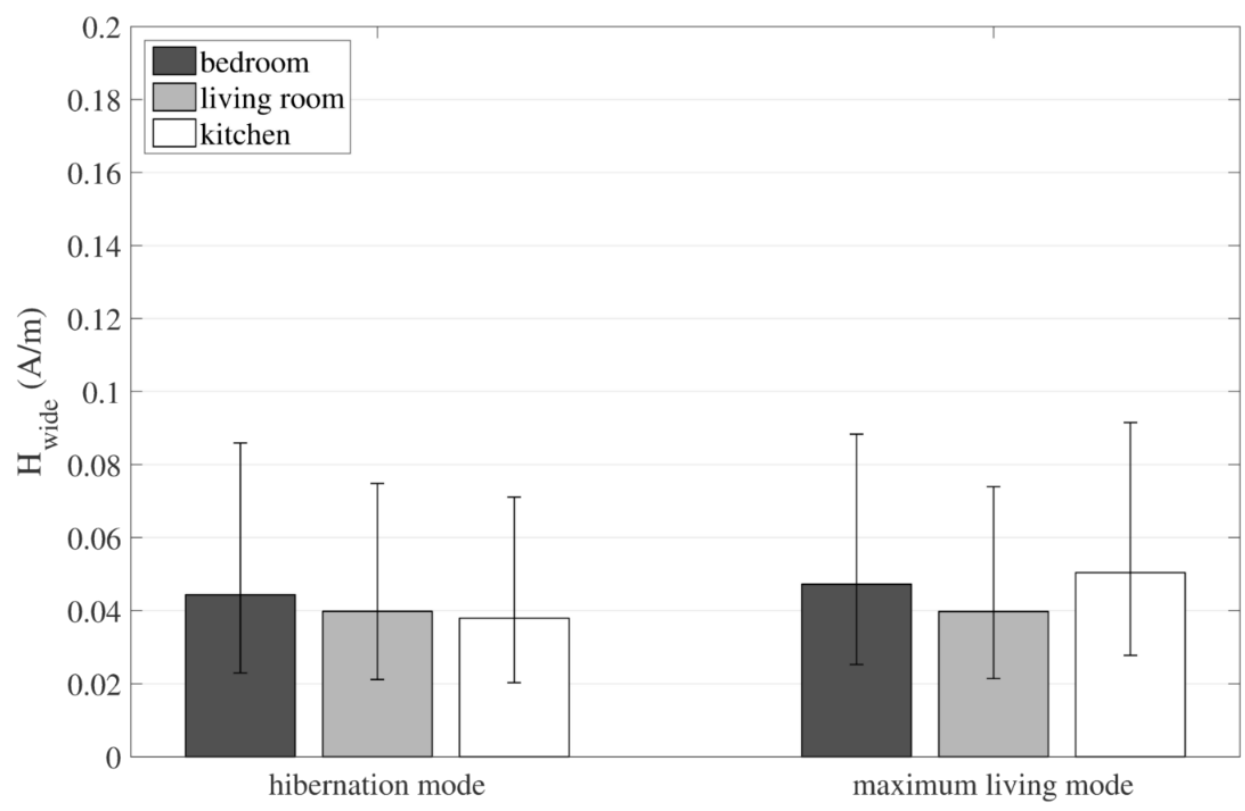

(b)

Figure 2: Geometric means (and geometric standard deviations) per room type (showing only the three most-frequented rooms: bedroom/living room/kitchen) and per room usage mode (hibernation/maximum living) of the (a) wideband electric-field strength $\left(\boldsymbol{E}_{\text {wide }}, \mathrm{V} / \mathrm{m}\right)$ and $(\mathrm{b})$ wideband magnetic-field strength $\left(\boldsymbol{H}_{\text {wide }}, \mathrm{A} / \mathrm{m}\right)$ measurements, collected over all rooms of the respective type in the $100 \mathrm{kHz}$ band (measured with $\mathrm{EHP}-50$ ).

\section{2. $\quad$ Source measurements}

\subsubsection{Overview}

\subsection{1. Appliances}

Per residence, between 2 and 19 electric appliances (on average 7) were identified as IF emitters. The total of 279 appliances were further classified into 65 categories (Table 3), of which power tools and compact fluorescent lamps were the largest. Four more categories consisted of more than ten appliances, and 32 categories contained only one. Three categories (i.e., fridges, laundry machines, and microwave ovens) were split in two because part of the appliances used inverter technology (IT), causing distinct IF emissions (see Section 3.3.1). Furthermore, for some categories, multiple measurements were performed for each individual appliance. For example, measurements were taken at different times during operating cycles of dishwashers and laundry machines, and measurements of electric toothbrush chargers were taken with and without the toothbrush connected. Hence, in these cases, the number of measurement samples ( $n_{s}$ in Table 3.2) is higher than the number of appliances (\#). 
Table 3: Categories of IF-field emitting household appliances, with \# representing the number of appliances, and $\mathbf{n}_{\mathrm{s}}$ the total number of measurement samples if there was a difference (see table footnotes). ( $\mathrm{AC}=$ alternating current, IT $=$ inverter technology, WLAN = wireless local area network.)

\begin{tabular}{|c|c|c|c|c|c|}
\hline Category & $\#\left(\mathbf{n}_{\mathbf{s}}\right)$ & Category & $\#\left(\mathbf{n}_{\mathbf{s}}\right)$ & Category & $\#\left(\mathbf{n}_{\mathbf{s}}\right)$ \\
\hline AC adapter & 6 & electric water boiler & 1 & portable radio & 1 \\
\hline air conditioning (IT) & 1 & electricity power saver & 1 & power tool & 48 \\
\hline baby monitor & 4 & exhaust hood & 3 & radio-controlled (RC) toy & 1 \\
\hline battery charger & 5 & fluorescent lamp & 5 & refrigerator (IT) & 1 \\
\hline blender & 7 & gaming console & 5 & refrigerator (non-IT) & 2 \\
\hline $\begin{array}{l}\text { cold-cathode fluorescent lamp } \\
\text { (CCFL) }\end{array}$ & 1 & hair drier & 5 & robot vacuum cleaner & 1 \\
\hline $\begin{array}{l}\text { compact fluorescent lamp } \\
\text { (CFL) }\end{array}$ & 28 & hair removal device & 5 & scanner & 1 \\
\hline clock fan & 1 & hair straightener & 1 & sewing machine & 1 \\
\hline coffee maker & 1 & halogen lamp & 2 & solar inverter & 1 \\
\hline compressor & 1 & heat pump & 1 & spotlight with transformer & 5 \\
\hline $\begin{array}{l}\text { cathode-ray tube (CRT) } \\
\text { display }\end{array}$ & 11 & hotplate & 2 & storage water heater ${ }^{5}$ & $1(2)$ \\
\hline dehumidifier & 2 & induction cooker & 12 & tablet & 1 \\
\hline dimmed lamp ${ }^{3}$ (non-CFL) & $7(11)$ & kitchen robot (blender) & 1 & toy motor & 1 \\
\hline dimmer switch ${ }^{3}$ & $9(11)$ & laundry machine ${ }^{1,2}$ (IT) & $6(16)$ & ultraviolet (UV) lamp & 1 \\
\hline dishwasher $^{2}$ & $7(17)$ & $\begin{array}{l}\text { laundry machine }{ }^{1,2} \text { (non- } \\
\text { IT) }\end{array}$ & $8(22)$ & vacuum cleaner $^{3}$ & $15(17)$ \\
\hline electric bicycle & 1 & $\begin{array}{l}\text { liquid-crystal display } \\
\text { (LCD) }\end{array}$ & 5 & vaporiser & 2 \\
\hline electric heater & 1 & $\begin{array}{l}\text { light-emitting diode } \\
\text { (LED) display }\end{array}$ & 1 & ventilation system & 2 \\
\hline electric massager & 1 & LED light & 3 & wake-up light & 1 \\
\hline electric meat slicer & 1 & living light & 1 & water pump & 1 \\
\hline electric piano & 1 & microwave oven (IT) & 5 & welding machine $\mathrm{e}^{5}$ & $1(2)$ \\
\hline electric toothbrush & 2 & microwave oven (non-IT) & 12 & WLAN router & 3 \\
\hline electric toothbrush charger ${ }^{4}$ & $3(6)$ & mp3-player & 1 & & \\
\hline
\end{tabular}

${ }^{1}$ Category includes both tumble driers and washing machines.

${ }^{2}$ Measurements were taken at different times during operating cycles.

${ }^{3}$ Measurements were taken at different power states.

${ }^{4}$ Measurements were taken with and without the toothbrush connected.

${ }^{5}$ Measurements were taken during 'standby' and 'active' modes.

\section{2. 1.2. Measurements}

All appliances assessed (Table 3) showed non-zero IF field emissions when measured with the NFA1000 meter. However, due to some of the low levels encountered and the sharp decrease in fields with distance, the fields for 24 out of the 65 categories of appliances investigated were not detectable at $20 \mathrm{~cm}$ and thus were not included in the summary of results (Table 4). Some of these appliances (e.g., compressor, portable radio, and vaporiser) did, however, emit strong EF and/or MF in the ELF range (data from EHP-50 $2 \mathrm{kHz}$ measurements, not shown here), which might explain the non-zero reading in the $2 \mathrm{kHz}$ to $1 \mathrm{MHz}$ band of the NFA-1000 meter. 
Table 4: Summary of the measurements of the categories containing at least one IF-field emitter. Ranges of wideband electric- $\left(\boldsymbol{E}_{\text {wide }}\right)$ and magnetic-field $\left(H_{\text {wide }}\right)$ strengths measured at $20 \mathrm{~cm}$ and $50 \mathrm{~cm}$ in the $100 \mathrm{kHz}$ band (with EHP-50) and characteristics of the observed spectra (last column), with $f_{f}$ the fundamental frequency (or range of $f_{f}$ ) and $\mathrm{N}(. .$.$) the region in which a heightened field strength without clear f_{f}$ was observed (see e.g., Figure 3b). Frequencies (in $\mathbf{k H z}$ ) in green indicate electric-field components only, in purple magnetic-field components only, and in black and bold both.

\begin{tabular}{|c|c|c|c|c|c|}
\hline \multirow{2}{*}{ category } & \multicolumn{2}{|c|}{$\boldsymbol{E}_{\text {wide }}(\mathbf{V} / \mathbf{m})$} & \multicolumn{2}{|c|}{$\boldsymbol{H}_{\text {wide }}(\mathbf{A} / \mathbf{m})$} & \multirow{2}{*}{$f_{f} / \mathrm{N}(\ldots)(\mathrm{kHz})$} \\
\hline & $20 \mathrm{~cm}$ & $50 \mathrm{~cm}$ & $20 \mathrm{~cm}$ & $50 \mathrm{~cm}$ & \\
\hline AC adapter & $0.66-1.73$ & $0.49-0.68$ & $0.08-0.10$ & $0.07-0.09$ & $58-70 *$ \\
\hline air conditioning (IT) & 0.69 & 0.49 & 0.03 & 0.02 & $21 *+N(160-215)$ \\
\hline baby monitor & $0.37-0.72$ & 0.43 & $0.02-0.03$ & 0.03 & N(1-100) / -- \\
\hline battery charger & $0.27-11.56$ & $0.24-3.01$ & $0.02-0.10$ & $0.02-0.11$ & $20+\mathbf{4 2}-\mathbf{6 5}^{*}$ \\
\hline blender & $0.55-1.86$ & $0.34-0.67$ & $0.05-0.68$ & $0.02-0.10$ & $\begin{array}{l}\mathrm{N}(1-400)+ \\
\mathrm{N}(1-40)\end{array}$ \\
\hline CCFL & 10.75 & 1.41 & 0.08 & 0.08 & $39 *$ \\
\hline CFL & $1.46-37.27$ & $0.88-15.45$ & $0.02-0.11$ & $0.02-0.10$ & $27-62 *$ \\
\hline clock fan & 0.36 & 0.30 & 0.03 & 0.03 & 63 \\
\hline CRT display & $0.93-22.81$ & $0.66-6.09$ & $0.09-0.40$ & $0.03-0.12$ & $\begin{array}{c}\mathrm{N}(1-5)+15.5+ \\
31 *\end{array}$ \\
\hline dimmed lamp (non-CFL) & $0.65-11.10$ & $0.44-2.99$ & $0.07-0.11$ & $0.06-0.10$ & $\mathrm{~N}(1-50)$ \\
\hline dimmer switch & $0.37-14.94$ & $0.41-3.61$ & $0.02-0.13$ & $0.02-0.10$ & $\mathrm{~N}(1-50)$ \\
\hline dishwasher & $0.18-0.61$ & $0.20-0.31$ & $0.01-0.03$ & $0.02-0.03$ & $\begin{array}{c}12+16+48+62 \\
/--\end{array}$ \\
\hline electric massager & 6.10 & 0.46 & 0.10 & 0.03 & $\begin{array}{l}\mathrm{N}(1-100)+ \\
\mathrm{N}(1-20)\end{array}$ \\
\hline electric meat slicer & 0.44 & 0.31 & 0.04 & 0.03 & $\begin{array}{l}\mathrm{N}(1-100)+ \\
\mathrm{N}(1-10)\end{array}$ \\
\hline electric toothbrush charger & $0.56-4.26$ & $0.53-1.15$ & $0.07-0.17$ & $0.06-0.09$ & $\begin{array}{c}21-23 *+ \\
39-42 *\end{array}$ \\
\hline exhaust hood & $0.20-0.44$ & $0.16-0.33$ & $0.02-0.04$ & 0.02 & $20+28 /--$ \\
\hline fluorescent lamp & $6.02-40.15$ & $0.69-15.42$ & $0.03-0.11$ & 0.03-0.09 & $35-51 * /--$ \\
\hline gaming console & $0.32-1.97$ & $0.16-0.73$ & $0.02-0.09$ & $0.02-0.03$ & $32-65 /--$ \\
\hline hair drier & $0.40-0.78$ & $0.26-13.85$ & $0.07-0.18$ & $0.02-0.08$ & $\mathbf{N}(\mathbf{1 - 2 0})$ \\
\hline induction cooker & $7.62-41.84$ & $2.68-11.81$ & $0.18-3.71$ & $0.03-0.82$ & $19-70^{*}$ \\
\hline laundry machine (IT) & $0.32-6.21$ & $0.23-1.15$ & $0.02-0.13$ & $0.02-0.10$ & $\begin{array}{c}\mathrm{N}(1-400)+8 *+ \\
\mathbf{1 5 *}+18 *+21 *+ \\
30 *+33-293\end{array}$ \\
\hline LCD & $0.34-42.70$ & $0.25-19.59$ & $0.03-0.72$ & $0.02-0.16$ & $\begin{array}{l}N(45-90)^{*}+ \\
45-67 * /--\end{array}$ \\
\hline LED light & $0.32-0.60$ & $0.25-0.30$ & $0.03-0.03$ & $0.02-0.03$ & $\mathrm{~N}(150-200)^{*}$ \\
\hline microwave oven (IT) & $0.45-2.47$ & $0.39-0.70$ & $0.29-1.43$ & $0.14-0.28$ & $\mathbf{N}(20-80)^{*}$ \\
\hline microwave oven (non-IT) & $0.20-0.83$ & $0.21-0.78$ & $0.02-0.29$ & $0.02-0.11$ & $\mathbf{N}(\mathbf{1 - 5 0}) /--$ \\
\hline mp3-player & 0.61 & 0.30 & 0.04 & 0.03 & 58 \\
\hline power tool & $0.31-19.78$ & $0.18-14.51$ & $0.03-2.28$ & $0.02-0.22$ & $16^{*}+\mathbf{N}(\mathbf{1}-\mathbf{4 0 0})$ \\
\hline $\mathrm{RC}$ toy & 0.61 & 0.30 & 0.19 & 0.03 & $\mathbf{N}(\mathbf{1 - 3 0})$ \\
\hline refrigerator $(\mathrm{IT})^{1}$ & 13.03 & 4.39 & 0.10 & 0.10 & $6 *$ \\
\hline robot vacuum cleaner & 0.39 & n.m. & 0.09 & n.m. & $9.5^{*}$ \\
\hline
\end{tabular}




\begin{tabular}{lllllc} 
scanner & 0.90 & 0.66 & 0.10 & 0.08 & 96 \\
sewing machine & 0.99 & 0.90 & 0.10 & 0.09 & $\mathrm{~N}(1-75)$ \\
\hline spotlight with transformer & $0.55-6.91$ & $0.76-2.40$ & $0.06-1.51$ & 0.10 & $\mathbf{1 5}^{*}+\mathrm{N}(32-60)+$ \\
$32-46^{*}$
\end{tabular}

At $20 \mathrm{~cm}$, wideband electric- $\left(E_{\text {wide }}\right)$ and magnetic- $\left(H_{\text {wide }}\right)$ field strengths were measured of up to $42.70 \mathrm{~V} / \mathrm{m}$ (liquid-crystal display (LCD); $19.59 \mathrm{~V} / \mathrm{m}$ at $50 \mathrm{~cm}$ ) and $3.71 \mathrm{~A} / \mathrm{m}$ (induction cooker; $0.82 \mathrm{~A} / \mathrm{m}$ at $50 \mathrm{~cm})$, respectively, with respective median values of $1.30 \mathrm{~V} / \mathrm{m}(0.67 \mathrm{~V} / \mathrm{m}$ at $50 \mathrm{~cm})$ and $0.09 \mathrm{~A} / \mathrm{m}(0.05 \mathrm{~A} / \mathrm{m}$ at $50 \mathrm{~cm})$. Furthermore, the IF-field spectra encountered in this study were found to be either well-defined and repeatable (e.g., CFLs or CRT displays, Figure 3a), or complex and erratic (e.g., blenders, Figure 3b). 


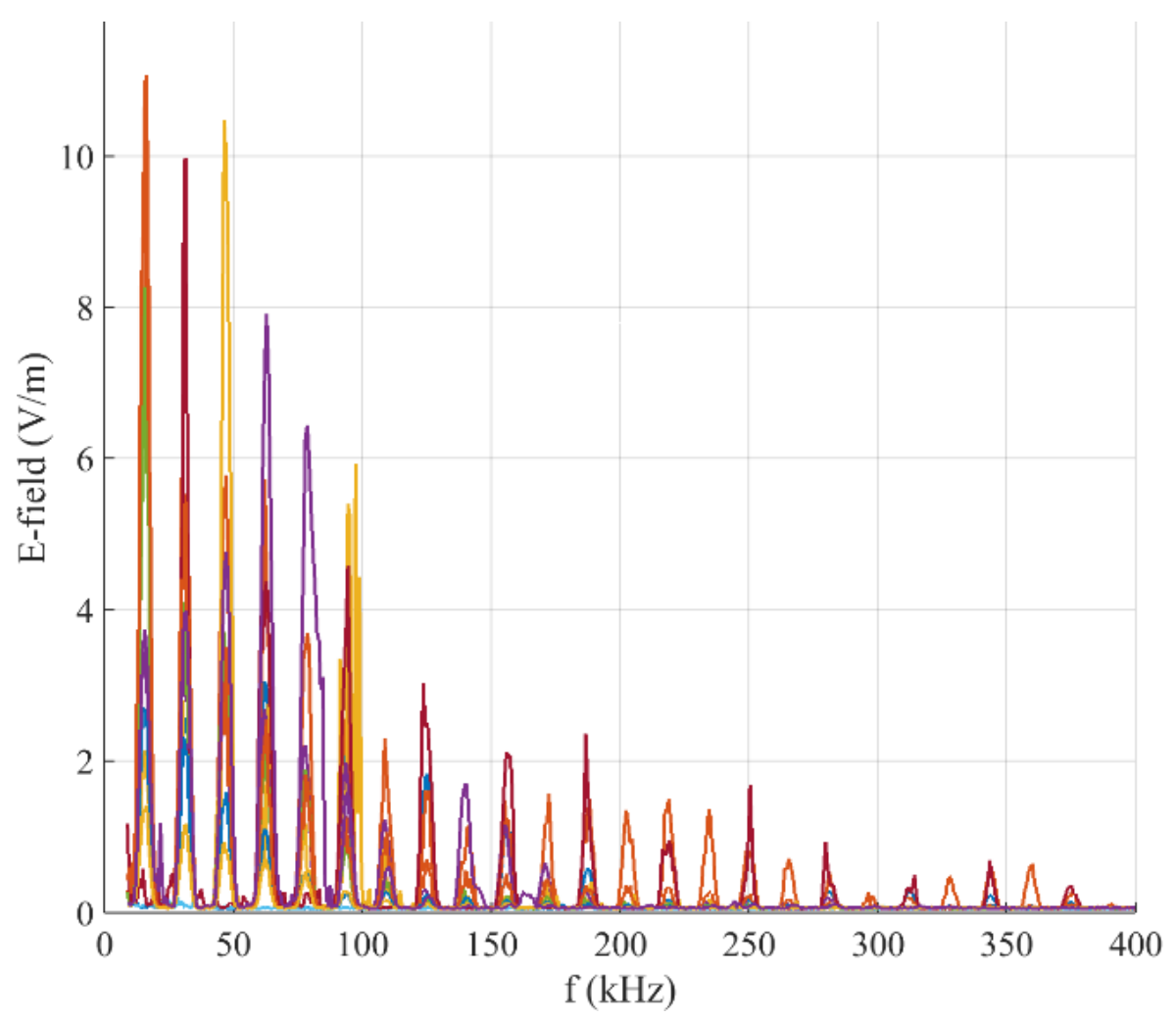

(a)

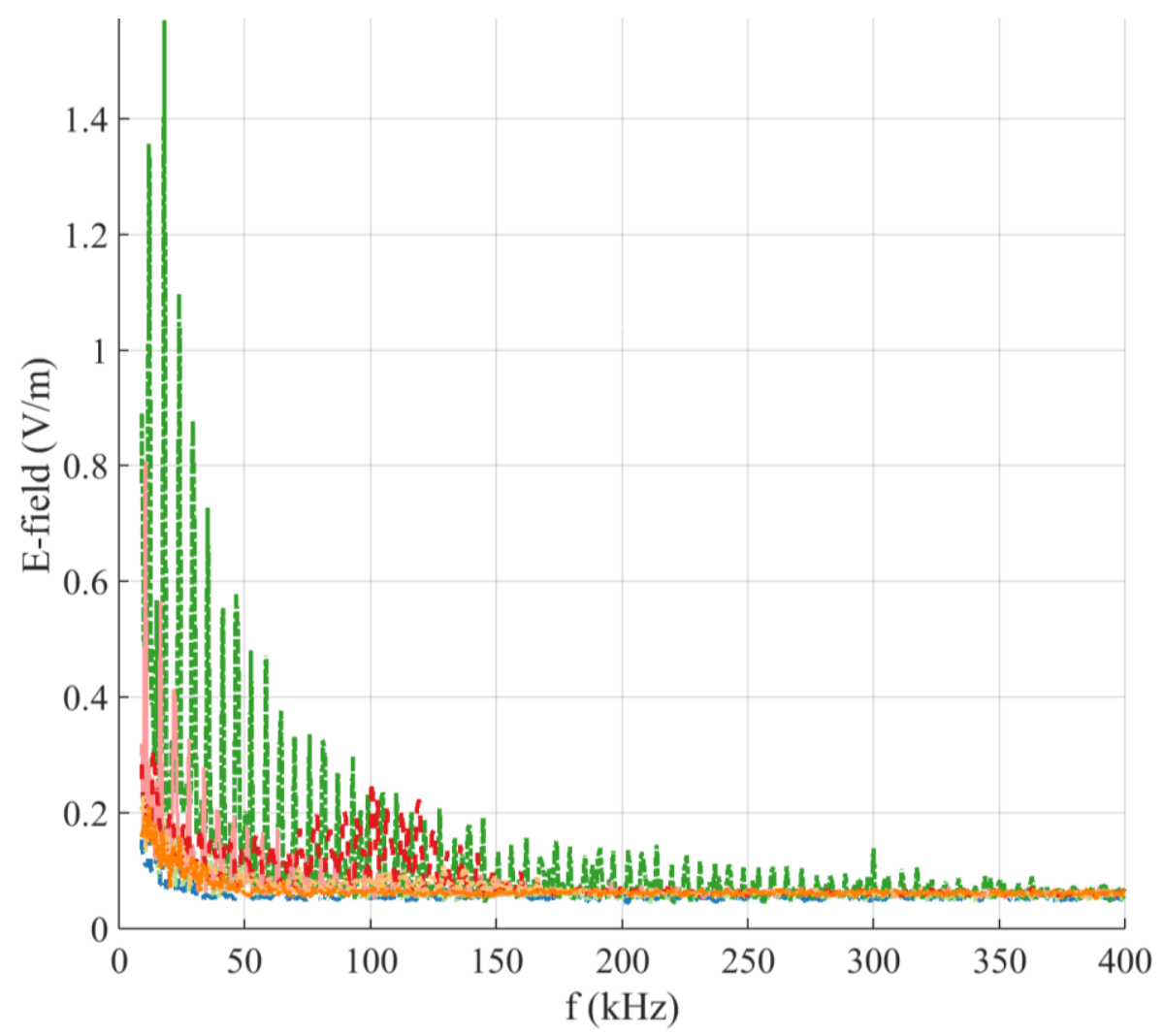

(b)

Figure 3: Examples of intermediate-frequency spectra (electric field) between $9 \mathrm{kHz}$ and $400 \mathrm{kHz}$ : (a) cathode ray tube (CRT) displays, and (b) blenders. All measurements with the appliances 'on' and performed at $20 \mathrm{~cm}$ were included. 
Figure 4 further offers a graphical overview of the range of the wideband EF and MF levels between $1 \mathrm{kHz}$ and $100 \mathrm{kHz}$ measured at a distance of $20 \mathrm{~cm}$ from the assessed sources. For clarity, only those categories with $n_{s}>3$ that contained at least one appliance for which either field value at $20 \mathrm{~cm}$ was higher than $1 \%$ of the respective reference level above $3 \mathrm{kHz}$ (i.e., $0.83 \mathrm{~V} / \mathrm{m}$ or $0.21 \mathrm{~A} / \mathrm{m}$ ) are shown here. Overall, the category with the (consistently) highest measured IF fields - EF and MF - was induction cooker (light-green area in Figure 4), after which LCD, power tools (albeit with a huge variation - see orange area in Figure 4), CFLs (and other fluorescent lighting), and microwave ovens (IT) generated the highest fields.

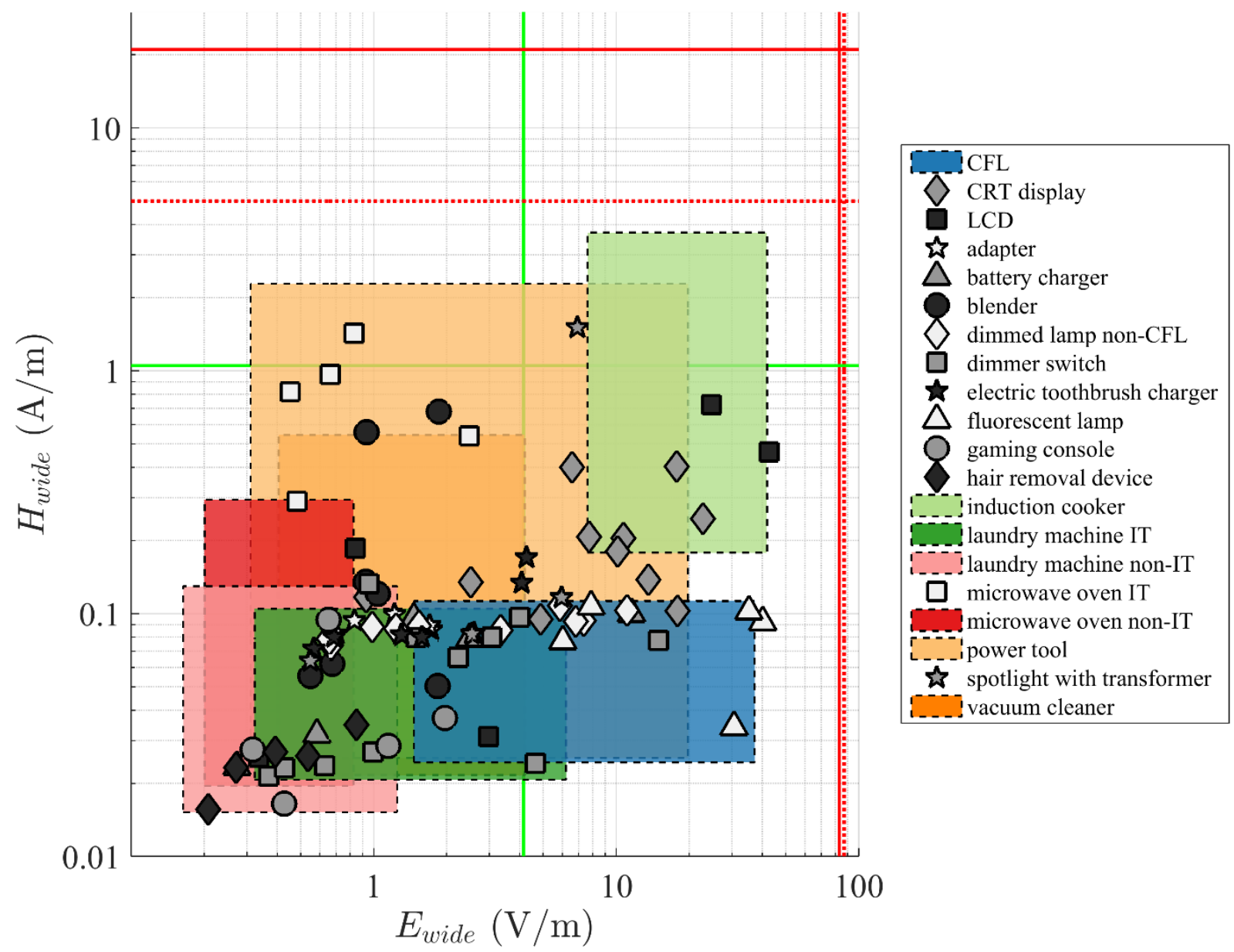

Figure 4: Wideband electric- $\left(E_{\text {wide }}, \mathrm{V} / \mathrm{m}\right)$ vs magnetic-field $\left(H_{\text {wide }}, \mathrm{A} / \mathrm{m}\right)$ levels in the $100 \mathrm{kHz}$ band measured at a distance of $20 \mathrm{~cm}$ to the source. The red lines are the ICNIRP reference levels (full: ICNIRP2010, dotted: ICNIRP1998), the green lines are the $5 \%$ borders. Shown here are only those categories for which $n_{\mathrm{s}}>\mathbf{3}$ and with at least one appliance with a measured field strength $\left(E_{\text {wide }} / H_{\text {wide }}\right)$ at $20 \mathrm{~cm}$ higher than $1 \%$ of either ICNIRP 2010 reference level above $3 \mathrm{kHz}$. Categories for which $\mathbf{n}_{\mathrm{s}}>11$ are represented by areas rather than single points.

\section{2. 1.3. Exposure quotient}

For each source, the IF-EQs were calculated using two methods - IEC 62233:2005 and ICNIRP 2010 (Equations (1) and (2) in Section 2.3). In Figure 5, these two methods were compared for both MF (blue diamonds) and EF (yellow circles) emissions. 


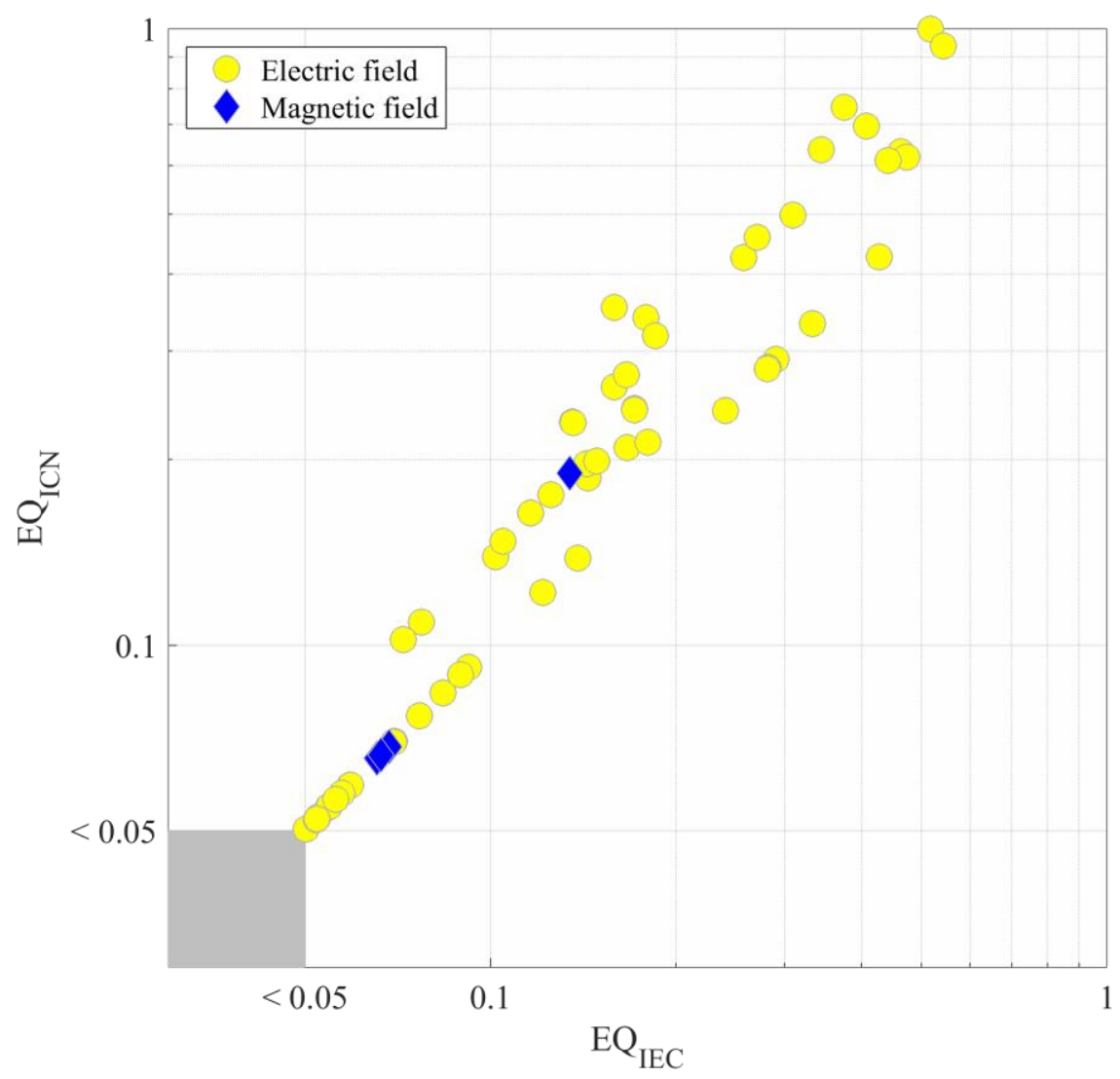

Figure 5: Electric-field (yellow dots) and magnetic-field (blue diamonds) exposure quotients at $20 \mathrm{~cm}$, calculated using IEC 62233:2005 (x-axis) and ICNIRP guidelines (y-axis).

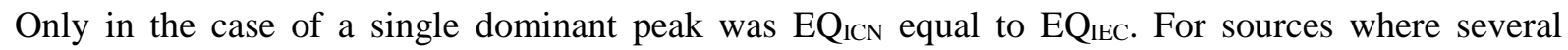
frequency components were above the 5\% threshold(e.g., multiple components of a broad peak, or multiple harmonics), $\mathrm{EQ}_{\mathrm{ICN}}$ was on average $56 \%$ higher, and maximally $112 \%$. Had we not restricted the contribution of spectral components to those above $5 \%$ of the reference levels (as it was not defined as such in the ICNIRP guideline), the difference would have been larger.

Although all IF-field emissions measured at $20 \mathrm{~cm}$ satisfied both guidelines $(\mathrm{EQ} \leq 1)$, fourteen categories were considered exposure-relevant, i.e., they included at least one source with EQ > 0.05 (see Section 3.2.2.). Finally, although some EQs were close (or equal) to 1, the ICNIRP reference levels are designed to be quite conservative, and only if exceeded, is a more comprehensive evaluation required, involving spatial averaging and/or dosimetric modelling, to confirm compliance with ICNIRP basic restrictions (ICNIRP, 2010).

\subsubsection{Specific sources}

In this Section, the 14 categories that are considered to be most relevant to IF exposure, with at least one (MF and/or EF) EQ > 0.05, are discussed in more detail. The ICNIRP exposure quotients at $20 \mathrm{~cm}$ are illustrated in Figure 6. The highest median $\mathrm{EQ}_{\mathrm{E}}(0.53)$ was found for induction cookers, although the maximum $\mathrm{EQ}_{\mathrm{E}}$ (1.00) was measured for a CFL (median: 0.22). Substantial $\mathrm{EQH}_{\mathrm{H}}$ 's (all outliers) were found for two induction cookers, one microwave oven with IT, and one power tool (a sanding machine). 
Furthermore, from the 14 categories, only five had median EQs above the threshold of 5\%, albeit in some categories there were not many samples. In this Section, any reported EQ refers to EQICN.

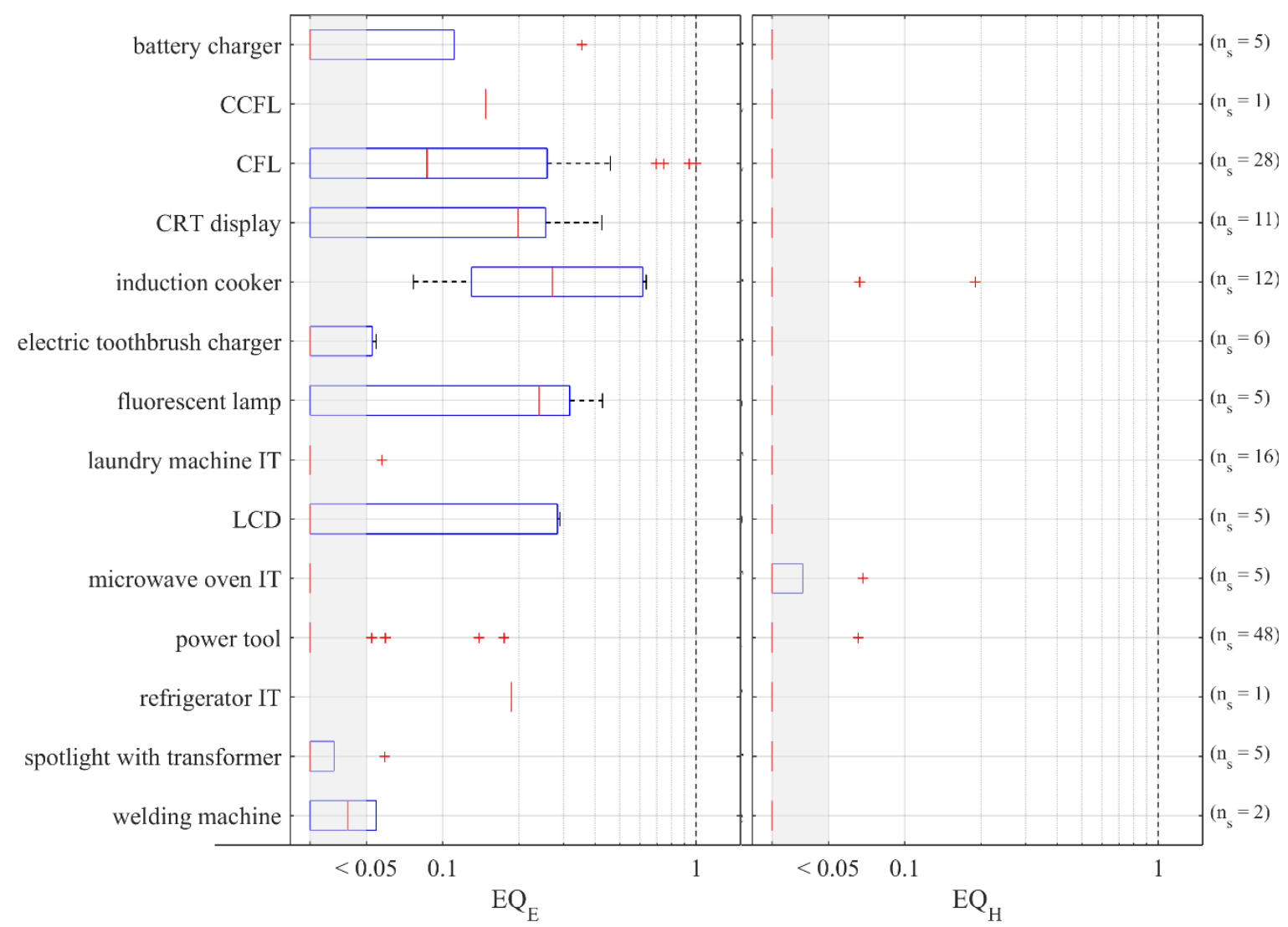

Figure 6: Electric-field (left) and magnetic-field (right) EQ boxplots showing median (red lines) as well as $25^{\text {th }}-\mathbf{7 5}^{\text {th }}$ percentile ranges (blue box) at $20 \mathrm{~cm}$ calculated following guidelines in ICNIRP 2010 for the relevant categories. All other categories only had EQs $<0.05$. EQs in the gray area are $<0.05$. (Red crosses are outliers. $\mathbf{n}_{\mathrm{s}}=$ number of samples.

Battery charger. All (five) assessed battery chargers emitted IF fields. Four of them emitted both IFEF and -MF, with fundamental frequencies $f_{f}$ between $42 \mathrm{kHz}$ and $65 \mathrm{kHz}$. For those battery chargers, $E_{\text {peak }, i}$ of up to $6.4 \mathrm{~V} / \mathrm{m}$ and $H_{\text {peak }, i}$ of up to $0.03 \mathrm{~A} / \mathrm{m}$ were measured at a distance of $20 \mathrm{~cm}$, and one of them had at this distance an $\mathrm{EQ}_{\mathrm{E}}$ of 0.35 due to five peaks above the $5 \%$ threshold. The fifth battery charger, in its turn, only emitted IF-EF, with a significantly lower $E_{\text {peak }}$ at $f_{f} 20 \mathrm{kHz}$ of $0.1 \mathrm{~V} / \mathrm{m}$ (at $20 \mathrm{~cm})$.

Cathode ray tube (CRT) display. Although a fast-disappearing technology, 11 screens using CRT technology were found in the study: eight televisions (TVs), one computer screen, and two videophones. In their EF and MF spectra, $f_{f}$ of $15.5 \mathrm{kHz}$ (in eight cases; six TVs and two videophones) and $31 \mathrm{kHz}$ (three remaining cases) were observed, with maximum $E_{\text {peak }, i}$ of $0.2-11 \mathrm{~V} / \mathrm{m}$ and maximum $H_{\text {peak }, i}$ of $<0.01-0.38 \mathrm{~A} / \mathrm{m}$ at $20 \mathrm{~cm}$ from the screen. In comparison, Kurokawa et al. (2004) measured maximum $H_{\text {peak }}$ between $10 \mathrm{kHz}$ and $150 \mathrm{kHz}$ above $0.40 \mathrm{~A} / \mathrm{m}$ at $10 \mathrm{~cm}$, and up to $0.26 \mathrm{~A} / \mathrm{m}$ at $50 \mathrm{~cm}$. Mantiply et al. (1997) further reported root-mean-square (RMS) EF strengths of $0.22-52 \mathrm{~V} / \mathrm{m}$ and RMS MF strengths of $0.26 \mathrm{~mA} / \mathrm{m}-0.17 \mathrm{~A} / \mathrm{m}$ at $30 \mathrm{~cm}$ from the screen centre. Finally, at a distance of $20 \mathrm{~cm}$, six 
CRT displays had a relevant $\mathrm{EQ}_{\mathrm{E}}$ of up to 0.43 , due to two to six single peaks, including sometimes a number of $50 \mathrm{~Hz}$ harmonics between $300 \mathrm{~Hz}$ and $5 \mathrm{kHz}$.

Cold-cathode fluorescent lamp (CCFL). Only one CCFL was assessed in this study $\left(\mathrm{EQ}_{\mathrm{E}} 0.15\right.$ at $20 \mathrm{~cm}$ ). While the EHP-50 $100 \mathrm{kHz}$ measurements indicated a sharp peak in the EF spectrum at $f_{f}$ $39 \mathrm{kHz}$, with at this frequency $E_{\text {peak }} 10.8 \mathrm{~V} / \mathrm{m}$ at $20 \mathrm{~cm}$, the EHP-200, on the other hand, measured around the same frequency a broad peak comprising two narrow peaks, with $E_{\text {peak }, i}$ of $5.4 \mathrm{~V} / \mathrm{m}$ and $6.8 \mathrm{~V} / \mathrm{m}($ at $20 \mathrm{~cm})$.

Compact fluorescent lamp (CFL). Except in the case of four CFLs with narrow peaks at $f_{f}$ between $27 \mathrm{kHz}$ and $31 \mathrm{kHz}$, all CFL EF spectra had broad peaks (typically $6 \mathrm{kHz}$ wide) at $f_{f}$ between $33 \mathrm{kHz}$ and $62 \mathrm{kHz}$, with $E_{\text {peak, } i}$ of up to $25 \mathrm{~V} / \mathrm{m}$. In 20 out of 28 samples, relevant $\mathrm{EQ}_{\mathrm{E}}$ of up to 1.00 were found at $20 \mathrm{~cm}$ (due to one to four peaks, often part of the same broad peak), and in one sample even at $50 \mathrm{~cm}$ (EQE 0.24$)$. MF were overall negligible in the IF range due to the symmetrical construction of the fluorescent tubes (Nadakuduti et al., 2012) (Table 4). It should be noted that, in this study, the distance to the edge of the lamp was used, which included the lampshade, if there was one.

Previous studies reported $E_{\text {peak }}$ exceeding the ICNIRP reference level at distances closer than $20 \mathrm{~cm}$ from the lamps (Bakos et al., 2010; Nadakuduti et al., 2012; Van den Bossche et al., 2015), with e.g., $E_{\text {peak }}$ of $117 \mathrm{~V} / \mathrm{m}$ at $5 \mathrm{~cm}$, and $97 \mathrm{~V} / \mathrm{m}$ at $15 \mathrm{~cm}$ (Van den Bossche et al., 2015). Furthermore, at a centreto-centre distance of $15 \mathrm{~cm}, \mathrm{EQ}_{\mathrm{E}}$ (calculated using $E_{R} 87 \mathrm{~V} / \mathrm{m}$ (ICNIRP, 1998), as opposed to $83 \mathrm{~V} / \mathrm{m}$ in this study) between 0.7 and 5.0 were reported across 11 CFLs by Nadakuduti et al. (2012). However, although the reference levels were exceeded, exposure was found to be below the basic restrictions.

Electric toothbrush charger. At both measuring distances, each electric toothbrush charger $(\#=3)$ was measured twice $\left(n_{s}=6\right)$; once with and once without the electric toothbrush placed on the charger. For all three chargers, $f_{f}$ shifted slightly when removing the toothbrush; once from $22.5 \mathrm{kHz}$ to $21.0 \mathrm{kHz}$, and twice from $42.2 \mathrm{kHz}$ to $39.5 \mathrm{kHz}$. Furthermore, in the first case, $H_{\text {peak }}$ increased (from $0.09 \mathrm{~A} / \mathrm{m}$ to $0.14 \mathrm{~A} / \mathrm{m}$ at $20 \mathrm{~cm}$ ) while maximum $E_{\text {peak }}$ remained the same $(4 \mathrm{~V} / \mathrm{m}$ at $20 \mathrm{~cm})$, and $\mathrm{EQ}_{\mathrm{E}}$ was 0.06 at $20 \mathrm{~cm}$. In the two other cases, both EF and MF intensities decreased when removing the toothbrush (at 20cm: $E_{\text {peak }}$ decreased from $\sim 1.1-1.4 \mathrm{~V} / \mathrm{m}$ to $0.3-0.4 \mathrm{~V} / \mathrm{m}$, and $H_{\text {peak }}$ from $\sim 0.03-0.04 \mathrm{~A} / \mathrm{m}$ to $0.02 \mathrm{~A} / \mathrm{m}$ ), and EQs were below 0.05 for all measurements.

Fluorescent lamp. In the EF and MF spectra of three fluorescent lamps, narrow peaks were observed in the IF range at $f_{f}$ between $35 \mathrm{kHz}$ and $51 \mathrm{kHz}$, with maximum $E_{\text {peak,i }}$ between $20 \mathrm{~V} / \mathrm{m}$ and $35 \mathrm{~V} / \mathrm{m}$ at $20 \mathrm{~cm}$ (at $50 \mathrm{~cm}: 8.0-13.5 \mathrm{~V} / \mathrm{m}$ ) and $H_{\text {peak, } \max } 0.01$ to $0.03 \mathrm{~A} / \mathrm{m}$. In these cases, the high IF-EF components resulted in $\mathrm{EQ}_{\mathrm{E}}$ of $0.24-0.43$ at $20 \mathrm{~cm}$, and of $0.09-0.15$ at $50 \mathrm{~cm}$. The two other fluorescent lamps were most likely of an older type, containing a conventional ballast (cf. second FL measured by Kurokawa et al. (2004)) and did not emit IF fields. The only previously published measurements of fluorescent (tube) lighting were done by Van den Bossche et al. (2015), who reported 
$f_{f}$ of $45 \mathrm{kHz}$ to $52 \mathrm{kHz}$, with a maximum $E_{\text {peak }}$ of $200 \mathrm{~V} / \mathrm{m}$ at $15 \mathrm{~cm}$, and by Kurokawa et al. (2004), who reported $H_{\text {wide }}$ (between $10 \mathrm{kHz}$ and $150 \mathrm{kHz}$ ) of over $0.04 \mathrm{~A} / \mathrm{m}$ at $10 \mathrm{~cm}$ and $0.01 \mathrm{~A} / \mathrm{m}$ at $50 \mathrm{~cm}$.

Induction cooker. Induction cookers emit both IF-EF and -MF. In this study, $f_{f}$ were found to vary between $19.5 \mathrm{kHz}$ and $70 \mathrm{kHz}$. In two cases, $f_{f}$ shifted during the measurement (in one of them, $f_{f}$ varied between $42 \mathrm{kHz}$ and $70 \mathrm{kHz}$ in-between measurements). At a measuring distance of $20 \mathrm{~cm}$, all twelve of them had the potential to produce considerable IF-EF exposure, with maximum $E_{\text {peak }}$ of $4.8 \mathrm{~V} / \mathrm{m}$ to 41.5 V/m, which resulted in $\mathrm{EQ}_{\mathrm{E}}$ between 0.08 and 0.63 (due to one to four single peaks), and for seven cookers still relevant $\mathrm{EQ}_{\mathrm{E}}$ at $50 \mathrm{~cm}$ of up to 0.13 . Moreover, maximum $H_{p e a k}$ at $20 \mathrm{~cm}$ ranged between $0.2 \mathrm{~A} / \mathrm{m}$ and $2.7 \mathrm{~A} / \mathrm{m}$, with two induction cookers generating above-threshold $\mathrm{EQ}_{\mathrm{H}}$ of up to 0.13. All induction cookers were assessed with one pot of $2-31$ of water placed on a cooking zone next to the cabinet edge and used at maximum power.

In contrast to other sources of IF fields identified in this study (with the exception of CFLs), detailed research is already available on induction cookers (Christ et al., 2012; Kos et al., 2011; Viellard et al., 2007). Unfortunately, most of these studies focused on MF only. Christ et al. (2012) measured dominant frequency components at $\sim 20 \mathrm{kHz}$ (with harmonics up to $400 \mathrm{kHz}$ ) and $H_{\text {peak }}$ of $0.16-1.2 \mathrm{~A} / \mathrm{m}$ at $30 \mathrm{~cm}$ for domestic cooktops; Mantiply et al. (1997) also reported fundamental frequencies between 22 and $34 \mathrm{kHz}, E \sim 4.6 \mathrm{~V} / \mathrm{m}$ and $H 0.7 \mathrm{~A} / \mathrm{m}-1.6 \mathrm{~A} / \mathrm{m}$ at $30 \mathrm{~cm}$.

It should be noted that, by using the ICNIRP $2010 \mathrm{MF}$ reference level for the general public (i.e., $21 \mathrm{~A} / \mathrm{m}$ between $3 \mathrm{kHz}$ and $150 \mathrm{kHz}$ ), as opposed to $5 \mathrm{~A} / \mathrm{m}$ (ICNIRP, 1998), the relevance of the MF exposure here is significantly reduced compared to older studies. In practice, any $H_{\text {peak }}$ below $1.05 \mathrm{~A} / \mathrm{m}$ is not considered in the EQ calculation, which, to put this into context, would mean that 15 out of the 16 induction cookers measured by Christ et al. (2012) would have below-threshold $\mathrm{EQ}_{\mathrm{H}}$ at $30 \mathrm{~cm}$, and just under half of the devices at touching distance.

Laundry machine with IT. In total, 14 laundry machines (11 washing machines and 3 tumble driers) were assessed: six of them (all washing machines) emitted detectable IF fields and were catalogued under 'laundry machine (IT)' (Table 3). Most of the laundry machines with IT were measured during different stages of a washing/drying cycle $\left(\mathrm{n}_{\mathrm{s}}=16\right)$. Though $f_{f}$ and peak field levels often seemed to vary between stages, no clear distinction between the stages was identified. One IT washing machine had an $\mathrm{EQ} \mathrm{E}_{\mathrm{E}}$ of 0.06 at $20 \mathrm{~cm}$ due to a maximum $E_{\text {peak }}$ of $4.7 \mathrm{~V} / \mathrm{m}$ at $f_{f} 8 \mathrm{kHz}$. The other laundry machines emitted much lower fields; one emitted both IF-EF and -MF at $f_{f} 15 \mathrm{kHz}$ (at $20 \mathrm{~cm}, H_{\text {peak }}$ up to $0.01 \mathrm{~A} / \mathrm{m}$ and $E_{\text {peak }}$ up to $1.4 \mathrm{~V} / \mathrm{m}$ ), one predominantly IF-MF ( $f_{f} 30 \mathrm{kHz}, H_{\text {peak }}$ up to $0.02 \mathrm{~A} / \mathrm{m}$ at $20 \mathrm{~cm}$ ), others solely IF-EF (at $f_{f}$ of $8 \mathrm{kHz}, 18 \mathrm{kHz}, 21 \mathrm{kHz}, 33 \mathrm{kHz}, 74 \mathrm{kHz}, 205 \mathrm{kHz}$, and $293 \mathrm{kHz}$ ), with $E_{\text {peak }}$ of up to about $0.5 \mathrm{~V} / \mathrm{m}$ at $20 \mathrm{~cm}$. In comparison, for one tumble drier, between $10 \mathrm{kHz}$ and $150 \mathrm{kHz}$ an $H_{\text {peak }}$ of $0.01 \mathrm{~A} / \mathrm{m}$ was measured by Kurokawa et al. (2004) at $10 \mathrm{~cm}$. 
Liquid-crystal display (LCD). One LCD-TV did not emit any IF fields. For the other four LCD screens, $f_{f}$ in the EF and MF spectra were observed at $45 \mathrm{kHz}$ (2 TVs), $57 \mathrm{kHz}$ (laptop), and $67 \mathrm{kHz}$ (TV; only EF). . The difference in $f_{f}$ can be attributed to the horizontal scan frequency. Furthermore, the LCD-TVs with $f_{f} 45 \mathrm{kHz}$ were most likely CCFL-back- or -edge-lit and had relevant EF exposure at $20 \mathrm{~cm}$ $\left(\mathrm{EQ}_{\mathrm{E}}=0.29\right)$ and $50 \mathrm{~cm}\left(\mathrm{EQ}_{\mathrm{E}}=0.20\right)$. Overall, at $20 \mathrm{~cm}$ from the centre of the screen, $E_{\text {peak }}$ and $H_{\text {peak }}$ ranges were $0.07-23 \mathrm{~V} / \mathrm{m}$ and $<0.01-0.70 \mathrm{~A} / \mathrm{m}$, respectively. In one of the LCD-TVs an additional increase in the EF spectrum between $45 \mathrm{kHz}$ and $90 \mathrm{kHz}$ was observed, which might be due to an automatic brightness adjustment option. Finally, the laptop screen generated a stronger MF (at $57 \mathrm{kHz}$ ) relative to its $\mathrm{EF}$ strength, compared to the two $45 \mathrm{kHz}$ TV sets.

Microwave oven with IT. Five of the assessed microwave ovens generated IF fields and were categorized under 'microwave oven (IT)' (Table 3). In the MF spectra of microwave ovens with IT, broad peaks were observed between $25 \mathrm{kHz}$ and $40 \mathrm{kHz}$ with maximum $H_{\text {peak }}$ of $0.4-0.8 \mathrm{~A} / \mathrm{m}$ at $20 \mathrm{~cm}$. Based on the EHP-200 $400 \mathrm{kHz}$ measurement, one IT microwave oven had at $20 \mathrm{~cm}$ an EQ $\mathrm{E}_{\mathrm{H}}$ of 0.07 , due to a maximum $H_{\text {peak }}$ of $1.44 \mathrm{~A} / \mathrm{m}$ at $70 \mathrm{kHz}$ (second harmonic. However, in the EHP-50 $100 \mathrm{kHz}$ measurement, the component at this frequency was much lower $(0.03 \mathrm{~A} / \mathrm{m})$, and the peak was actually observed at the fundamental frequency $(0.17 \mathrm{~A} / \mathrm{m})$. Moreover, the EF spectra measured with the two probes were also inconsistent. The EHP-200 measured peaks in the $30-50 \mathrm{kHz}$ and $50-80 \mathrm{kHz}$ ranges (and corresponding harmonics) with maximum $E_{\text {peak }}$ of $0.60-2.45 \mathrm{~V} / \mathrm{m}$, whereas in the EHP-50 measurements, these peaks were usually lower, or not even present.

Power tools. The power-tool category is much broader than any other defined in Table 3 and encompasses anything 'large' that is powered by fuel or electricity (mains or battery) and is actively handled by a person (often in the garden). A breakdown of the 48 considered power tools is given in Table 5. Relatively high field values were sometimes measured (Figure 4), and four power tools had notable EQs: two chainsaws ( $\left.\mathrm{EQ}_{\mathrm{E}} 0.06-0.14\right)$, an oscillating sander $\left(\mathrm{EQ}_{\mathrm{E}} 0.05\right)$, and a sanding machine ( $\mathrm{EQ}_{\mathrm{E}} 0.18$ and $\mathrm{EQ}_{\mathrm{H}}$ 0.07). The relatively high IF exposure was mainly due to a series of peaks composing capricious spectra both for EF and MF (such as in Figure 3b), possibly power-frequency harmonics ranging far into the IF range. Only one of the considered power tool appliances had a real fundamental frequency in the IF range (an electric drill with $f_{f} 16 \mathrm{kHz}$ ).

It should further be noted that also in the ELF range (data not shown), the emitted fields were sometimes found to be relatively high, i.e., at 5\% of the ICNIRP 2010 reference level for the general public.

Refrigerator with IT. A systematic error occurred during the EHP-50 $100 \mathrm{kHz}$ measurement while measuring this source, so the fundamental spectral component at $6 \mathrm{kHz}$ was extrapolated from harmonic signals at $12 \mathrm{kHz}, 18 \mathrm{kHz}$, etc. observed in the EHP-200 $400 \mathrm{kHz}$ measurement. At $20 \mathrm{~cm}$, a maximum $E_{\text {peak }}$ of $11.13 \mathrm{~V} / \mathrm{m}$ was measured at $12 \mathrm{kHz}$ (second harmonic), which resulted in an $\mathrm{EQE}_{\mathrm{E}}$ of 0.19. 
Table 5: List of power tools (\# = number of appliances).

\begin{tabular}{cccccc}
\hline Tool & $\#$ & Tool & $\#$ & Tool & $\#$ \\
\hline Angle grinder & 1 & $\begin{array}{c}\text { Garden } \\
\text { shredder }\end{array}$ & 1 & Leaf blower & 2 \\
Belt sander & 1 & Garden tiller & 1 & Mitre saw & 1 \\
Biscuit cutter & 1 & $\begin{array}{c}\text { Garden } \\
\text { trimmer }\end{array}$ & 1 & $\begin{array}{c}\text { Oscillating } \\
\text { sander }\end{array}$ & 1 \\
Brush cutter & 1 & Grinder & 2 & Planer & 1 \\
Chainsaw & 5 & Hedge trimmer & 5 & Router & 1 \\
Circular saw & 1 & Jigsaw & 4 & Sander & 4 \\
Electric drill & 8 & Lawnmower & 5 & Saw & 1 \\
\hline
\end{tabular}

Spotlight with transformer. Based on the spectra of the measured spot-lights-with-transformers, a distinction was made between (a) two magnetic transformers, for which high ELF-MF ( $H_{p e a k}$ at $50 \mathrm{~Hz}$ of up to $5.82 \mathrm{~A} / \mathrm{m}$ at $20 \mathrm{~cm}$ ) and low ELF-EF ( $E_{\text {peak }}$ at $50 \mathrm{~Hz}$ of up to $4 \mathrm{~V} / \mathrm{m}$ at $20 \mathrm{~cm}$ ) were observed, and no IF emissions; (b) three regular electronic transformers with IF-EF emissions at $f_{f}$ of $32-46 \mathrm{kHz}$ (and corresponding uneven harmonics up to $\sim 250 \mathrm{kHz}$ ), of which one had an $\mathrm{EQ}_{\mathrm{E}}$ of 0.06 due to a maximum $E_{\text {peak }}$ of $4.9 \mathrm{~V} / \mathrm{m}$; and (c) one transformer with a slow-start circuit, with a $50 \mathrm{~Hz}$ EF component of $130 \mathrm{~V} / \mathrm{m}$ and IF-EF and -MF emissions at an $f_{f}$ of $15 \mathrm{kHz}$, but not generating relevant IF exposure.

Welding machine. One welding machine - a manual metal arc (MMA) welder - was assessed. On standby (i.e., switched on but not actively welding) an $\mathrm{EQ}_{\mathrm{E}}$ of 0.05 was found at $20 \mathrm{~cm}$, due to a peak at $f_{f} 98 \mathrm{kHz}$, and no MF components were detected. When welding, however, the peaks in the EF spectrum decreased ( $E_{\text {peak }}$ at $98 \mathrm{kHz}$ was reduced from $4.5 \mathrm{~V} / \mathrm{m}$ to $2.4 \mathrm{~V} / \mathrm{m}$, so the EQ dropped below 0.05 ) or disappeared (third harmonic), while at the same time, peaks appeared in the MF spectrum at $99 \mathrm{kHz}$ $\left(H_{\text {peak }}\right.$ of $\left.0.12 \mathrm{~A} / \mathrm{m}\right)$ and its second harmonic.

\subsection{Overall Discussion}

At a certain distance (>1 m) from any electric appliance, IF field levels in residences were found to be generally low, with average wideband field strengths between $1 \mathrm{kHz}$ and $100 \mathrm{kHz}$ of approximately $1 \mathrm{~V} / \mathrm{m}$ and below $0.05 \mathrm{~A} / \mathrm{m}$ (i.e., the probes' noise floor). Measurements in the middle of the room actually showed only a minor increase in absolute EF strengths (on average $(\mathrm{GM})+0.7 \mathrm{~V} / \mathrm{m}$, maximum $+9.5 \mathrm{~V} / \mathrm{m}$ ) when in maximum living mode as compared to hibernation mode (no IF-MF were measured at a distance of $>1 \mathrm{~m}$ from an electric appliance).

At a distance of $20 \mathrm{~cm}$ (or closer), however, IF field emissions from certain appliances (especially induction cookers, CRT displays, LCDs, CFLs and other fluorescent lighting, some power tools, and some microwave ovens with IT) can become relevant, i.e., with a total IF-EF or -MF exposure above 
$5 \%$ of the ICNIRP reference levels, using IEC or ICNIRP summation rules. Overall, fundamental frequencies of IF emitting appliances varied between $6 \mathrm{kHz}$ (refrigerator with inverter technology) and $293 \mathrm{kHz}$ (laundry machine with inverter technology) with most somewhere between $20 \mathrm{kHz}$ and $60 \mathrm{kHz}$. Often, the $f_{f}$ were accompanied by harmonics (up to $400 \mathrm{kHz}$ for strong emitters such as induction cookers), and sometimes also by regions of 'noisy' elevated field strengths (e.g., spotlights with transformers and some LCD-TVs). However, in some cases, the observed spectra were much noisier and seemed to be dominated by $50 \mathrm{~Hz}$ harmonics emanating far in the IF domain (e.g., blenders (Figure 3b), dimmer switches, and power tools).

\subsubsection{Inverter technology}

During the study, IF fields were particularly evident in devices using 'inverter technology' (IT). IT is utilised in the design of some microwave ovens, refrigerators, laundry machines, and air conditioning systems, and offers better control (speed or temperature) and a higher energy efficiency. Due to the presence of IF fields in appliances with IT, the categories microwave oven, refrigerator, and laundry machine were split up (Table 3).

However, the IT did not appear in the measured spectra in the same way for all these appliances. In the case of microwave ovens, for example, broad peaks were observed in both the MF spectrum between $20 \mathrm{kHz}$ and $40 \mathrm{kHz}$ and in the EF spectrum between $20 \mathrm{kHz}$ and $100 \mathrm{kHz}$. The refrigerator with IT, on the other hand, had an $f_{f}$ in the EF spectrum at $6 \mathrm{kHz}$, and the air-conditioning system showed IF-EF emissions at three frequencies $(20 \mathrm{kHz}, 40 \mathrm{kHz}$, and $200 \mathrm{kHz})$. Finally, the spectra of the assessed laundry machines with IT were much more erratic, with EF and (to a lesser degree) MF emissions at $f_{f}$ between $15 \mathrm{kHz}$ and $293 \mathrm{kHz}$.

\subsubsection{Strengths and limitations}

In this study, a wealth of measurement data on EF and MF levels at IF were collected, spanning 42 properties and 279 appliances (65 categories) over three countries. IF exposure-relevant household appliance categories that were not previously described in the literature include power tools, electric toothbrush and battery chargers, LCDs, and appliances with inverter technology. For appliances that have been assessed in previous studies, e.g., induction cookers, CFLs, and CRTs, the measurements here are in line with those reported in those studies. The information provided here fills a gap in knowledge in terms of typical human exposures to IF-EF and -MF, and will be useful, in combination with appliance usage data, in epidemiological studies investigating potential links between (adverse) health effects and exposure to IF fields.

Although this paper compares the field levels at a given distance, it should be emphasised that actual exposure will depend on typical user distance to the appliance (e.g., the use of an LCD-TV or LCDlaptop) and on duration and frequency of use of the appliance. Additionally, the spatial combination of 
multiple sources (e.g., fluorescent lighting installed above an induction cooker) should be taken into account in any extensive IF exposure assessment.

Moreover, no measurements were performed at closer distance, because, besides becoming more unreliable, their relevance to exposure assessment would be questionable, as the majority of these appliances are unlikely to be used at distances closer than $20 \mathrm{~cm}$.

The possible temporal variation in the emitted fields has not been accounted for in this study, and this could be the cause of the occasional discrepancy between the EHP-50 and EHP-200 measurements. Moreover, for several appliances, no IF emissions were measured above the EHP measurement sensitivity at the distances investigated, even though in all cases, contributions in the $2 \mathrm{kHz}$ to $1 \mathrm{MHz}$ band had been measured with the NFA meter - although possibly at distances closer than $20 \mathrm{~cm}$. The fact that field levels were below the sensitivity of the EHP probes at the distances investigated but not in the NFA-1000 measurements shows how quickly the emitted fields can decay with distance, and show that even though quite a few appliances may have components emitting in the IF range, they would fall to very low levels, below the sensitivity of our measurement equipment at a distance of $20 \mathrm{~cm}$ or less.

\section{Conclusions}

Measurements of electric and magnetic fields at intermediate frequencies (IF) were performed in residences in three countries by way of a common protocol. Typical IF fields in the most frequented rooms were assessed as well as emissions from a wide range of household appliances. At distances of $1 \mathrm{~m}$ or more from the IF sources, field levels were found to be generally low. However, use of certain appliances at close distances $(20 \mathrm{~cm}$ to $50 \mathrm{~cm}$ ), including induction cookers, LCD screens, microwave ovens and refrigerators with inverter technology, and (compact) fluorescent lighting, may result in exposures above $5 \%$ of public ICNIRP2010 reference levels. In general, EF and MF emissions of household appliances in the IF range contained either harmonic signals, with fundamental frequencies between 6 and $293 \mathrm{kHz}$, which were sometimes accompanied by regions in the IF spectrum of rather noisy, elevated field strengths, or much more capricious spectra, seemingly dominated by $50 \mathrm{~Hz}$ harmonics emanating far in the IF domain. The maximum peak field strengths recorded in this study were $41.5 \mathrm{~V} / \mathrm{m}$ and $2.7 \mathrm{~A} / \mathrm{m}$ (both resulting from induction cookers) and at $20 \mathrm{~cm}$ and beyond none of the appliances exceeded the ICNIRP and IEC exposure summation rules (maximum observed electricand magnetic-field exposure quotients were 1.00 and 0.13 , respectively). The results reported here may provide a useful resource for epidemiological studies investigating the potential link between (adverse) health effects and exposure to IF fields. 


\section{References}

Addari M, Bessi F, Bottauscio O, Crotti G, D’Amore G, Tofani S, Gallimberti I, Tromboni U, Molinari G, Repetto M. 1994. Household ELF environment assessment. International Symposium on Electromagnetic Compatibility, EMC 94, 21-26. Rome, Italy.

Aerts S, Verloock L, Martens L, Joseph W. 2014. Compliance boundaries for train protection systems. Radiat. Prot. Dosimetry 158:68-72. http://www.ncbi.nlm.nih.gov/pubmed/23864643

Ainsbury EA, Conein E, Hensham DL. 2005. An investigation into the vector ellipticity of extremely low frequency magnetic fields from appliances in UK homes. Phys. Med. Biol. 50:3197-3209.

Alanko T, Puranen L, Hietanen M. 2011. Assessment of exposure to intermediate frequency electric fields and contact currents from a plasma ball. Bioelectromagnetics 32:644-651.

Bakos J, Nagy N, Juhász P, Thuróczy G. 2010. Spot measurements of intermediate frequency electric fields in the vicinity of compact fluorescent lamps. Radiat. Prot. Dosimetry 142:354-7. http://www.ncbi.nlm.nih.gov/pubmed/20924120

Christ A, Guldimann R, Bühlmann B, Zefferer M, Bakker JF, van Rhoon GC, Kuster N. 2012. Exposure of the human body to professional and domestic induction cooktops compared to the basic restrictions. Bioelectromagnetics 33:695-705. http://www.ncbi.nlm.nih.gov/pubmed/ 22674188

Environmental Protection Agency (EPA). 1992. EMF in Your Environment: Magnetic Field Measurements of Everyday Electrical Devices. United States Environmental Protection Agency (EPA), 402-R-92-008.

Floderus B, Stenlund C, Carlgren F. 2002. Occupational exposures to high frequency electromagnetic fields in the intermediate range (>300 $\mathrm{Hz}-10 \mathrm{MHz}$ ). Bioelectromagnetics 23:568-577. http://doi.wiley.com/10.1002/bem.10050

Gajšek P, Ravazzani P, Grellier J, Samaras T, Bakos J, Thuróczy G. 2016. Review of Studies Concerning Electromagnetic Field (EMF) Exposure Assessment in Europe: Low Frequency Fields (50 Hz-100 kHz). Int. J. Environ. Res. Public Health 2016, 13(9), 875; http://www.mdpi.com/1660$\underline{4601 / 13 / 9 / 875 / h t m}$

Harris C, Boivin W, Boyd S, Coletta J, Kerr L, Kempa K, Aronow S. 2000. Electromagnetic field strength levels surrounding electronic article surveillance (EAS) systems. Health Phys. 78.

International Commission on Non-Ionizing Radiation Protection (ICNIRP). 1998. Guidelines for limiting exposure to time-varying electric, magnetic, and electromagnetic fields (up to $300 \mathrm{GHz}$ ). Health Phys. 74:494-522. 
International Commission on Non-Ionizing Radiation Protection (ICNIRP). 2010. Guidelines for limiting exposure to time-varying electric and magnetic fields (1 Hz to $100 \mathrm{kHz})$. Health Phys. 99:81836.

International Electrotechnical Commission (IEC). 2005. IEC 62233:2005. Measurement methods for electromagnetic fields of household appliances and similar apparatus with regard to human exposure. Geneva, Switzerland.

Institute of Electrical and Electronics Engineers (IEEE). 2006. C95.1-2005 - IEEE standard for safety levels with respect to human exposure to radio frequency electromagnetic fields, $3 \mathrm{kHz}$ to $300 \mathrm{GHz}$.

Ishihara S, Onishi T, Hirata A. 2015. Magnetic Field Measurement for Human Exposure Assessment near Wireless Power Transfer Systems in Kilohertz and Megahertz Bands. IEICE Trans. Commun. E98$\mathrm{B}(12): 2470-2476$.

Joseph W, Goeminne F, Vermeeren G, Verloock L, Martens L. 2012a. Occupational and public field exposure from communication, navigation, and radar systems used for air traffic control. Heal. Phys 103:750-762. http://www.ncbi.nlm.nih.gov/pubmed/23111522

Joseph W, Goeminne F, Vermeeren G, Verloock L, Martens L. 2012b. In situ exposure to nondirectional beacons for air traffic control. Bioelectromagnetics 33:274-7. http://www.ncbi.nlm.nih.gov/pubmed/22252685

Joseph W, Vermeeren G, Verloock L, Goeminne F. 2012c. In situ magnetic field exposure and ICNIRPbased safety distances for electronic article surveillance systems. Radiat. Prot. Dosimetry 148:420-7. http://www.ncbi.nlm.nih.gov/pubmed/21613266.

Kang G, Gandhi OP. 2003. Comparison of various safety guidelines for electronic article surveillance devices with pulsed magnetic fields. IEEE Trans. Biomed. Eng. 50:107-13. http://www.ncbi.nlm.nih.gov/pubmed/12617530

Karipidis KK and Martin LJ. 2005. Pilot Study of Residential Power frequency Magnetic Fields in Melbourne. Technical report series. Australian Radiation Protection and Nuclear Safety Agency, 142. Yallambie, Australia.

Kos B, Valič B, Miklavčič D, Kotnik T, Gajšek P. 2011. Pre- and post-natal exposure of children to EMF generated by domestic induction cookers. Phys. Med. Biol. 56:6149-60. http://www.ncbi.nlm.nih.gov/pubmed/21878710

Kurokawa Y, Nitta H, Kabuto M. 2004. Evaluation of residential exposure to intermediate frequency magnetic fields. Arch. Environ. Health 59:693-9. http://www.ncbi.nlm.nih.gov/pubmed/16789479 
Leitgeb N, Cech R, Schröttner J, Lehofer P, Schmidpeter U, Rampetsreiter M. 2008a. Magnetic emission ranking of electrical appliances. A comprehensive market survey. Radiat. Prot. Dosimetry 129:439-45. http://www.ncbi.nlm.nih.gov/pubmed/18033762

Leitgeb N, Cech R, Schröttner J. 2008b. Electric emissions from electrical appliances. Radiat. Prot. Dosimetry 129:446-55. http://www.ncbi.nlm.nih.gov/pubmed/18083998

Liljestrand B, Sandström M, Mild KH. 2003. RF Exposure During Use of Electrosurgical Units. Electromagn. Biol. Med. 22:127-132.

Litvak E, Foster KR, Repacholi MH. 2002. Health and Safety Implications of Exposure to Electromagnetic Fields in the Frequency Range $300 \mathrm{~Hz}$ to $10 \mathrm{MHz}$. Bioelectromagnetics 23:68-82.

Mantiply ED, Pohl KR, Poppell SW, Murphy JA. 1997. Summary of measured radiofrequency electric and magnetic fields $(10 \mathrm{kHz}$ to $30 \mathrm{GHz})$ in the general and work environment. Bioelectromagnetics 18:563-77. http://www.ncbi.nlm.nih.gov/pubmed/9383245

Martínez-Búrdalo M, Sanchis A, Martín A, Villar R. 2010. Comparison of SAR and induced current densities in adults and children exposed to electromagnetic fields from electronic article surveillance devices. Phys. Med. Biol. 55:1041-55. http://www.ncbi.nlm.nih.gov/pubmed/20090190

Nadakuduti J, Douglas M, Capstick M, Kühn S, Kuster N. 2012. Application of an induced field sensor for assessment of electromagnetic exposure from compact fluorescent lamps. Bioelectromagnetics 33:166-175. http://doi.wiley.com/10.1002/bem.20696

Nelson RM and Ji H. 1999. Electric and magnetic fields created by electrosurgical units. IEEE Trans. Electromagn. Compat. 41:55-64.

Preece AW, Kaune W, Grainger P, Preece S, Golding J. 1997. Magnetic fields from domestic appliances in the UK. Phys. Med. Biol. 42:67-76.

Roivainen P, Eskelinen T, Jokela K, Juutilainen J. 2014. Occupational exposure to intermediate frequency and extremely low frequency magnetic fields among personnel working near electronic article surveillance systems. Bioelectromagnetics 35:245-250. http://www.ncbi.nlm.nih.gov/pubmed/24615825

Sunohara T, Hirata A, Laakso I, De Santis V, Onishi T. 2015. Evaluation of nonuniform field exposures with coupling factors. Phys. Med. Biol. 60(20):8129-8140.

Stuchly MA, Lecuyer DW. 1987. Electromagnetic fields around induction heating stoves. J. Microw. Power Electromagn. Energy 22:63-69. http://jmpee.org/JMPEE PDFs/22-2 bl/JMPEE-Vol22-Pg63Stuchly.pdf 
Tomitsch J, Dechant E. 2015. Exposure to electromagnetic fields in households-Trends from 2006 to 2012. Bioelectromagnetics 36:77-85. http://doi.wiley.com/10.1002/bem.21887.

Trulsson J, Anger G, Estenberg U. 2007. Assessment of magnetic fields surrounding electronic article surveillance systems in Sweden. Bioelectromagnetics 28:664-6. http://www.ncbi.nlm.nih.gov/pubmed/17786978

UK Childhood Cancer Study Investigators (UKCCS). 2000. The United Kingdom Childhood Cancer Study: objectives, materials and methods. Br. J. Cancer 82:1073-102. http://www.pubmedcentral.nih.gov/articlerender.fcgi?artid=2374433\&tool=pmcentrez\&rendertype $=\mathrm{ab}$ $\underline{\text { stract }}$

Van den Bossche M, Verloock L, Aerts S, Joseph W, Martens L. 2015. In situ exposure assessment of intermediate frequency fields of diverse devices. Radiat. Prot. Dosimetry 164:252-264. http://rpd.oxfordjournals.org/cgi/doi/10.1093/rpd/ncu257

Vereinigung der Metall-Berufsgenossenschaften (VMBG). 2003. BGI 839 - Elektromagnetische Felder in Metallbetrieben http://www.bghm.de/fileadmin/user_upload/Arbeitsschuetzer/Gesetze_ Vorschriften/BG-Informationen/BGI_839.pdf.

Viellard C, Romann A, Lott U, Kuster N. 2007. B-field exposure from induction cooking appliances. IT'IS Foundation, Zürich, Switzerland. http://www.bag.admin.ch/themen/strahlung/ $\underline{00053 / 00673 / 03156 / \text { index.html }}$

Wilén J. 2010. Exposure assessment of electromagnetic fields near electrosurgical units. Bioelectromagnetics 31:513-518. http://doi.wiley.com/10.1002/bem.20588

World Health Organization (WHO). 2005. Electromagnetic fields and public health - Intermediate frequencies (IF) Information sheet. Online available on http://www.who.int/pehemf/publications/facts/intermediatefrequencies_infosheet.pdf [Last accessed: December 22, 2016] 